\title{
Photoswitchable antagonists for a precise spatiotemporal control of $\beta_{2}$-adrenoceptors
}

Anna Duran-Corbera ${ }^{\dagger}$, Juanlo Catena ${ }^{\dagger \S}$, Marta Otero-Viñas ${ }^{\ddagger}$, Amadeu Llebaria $^{\dagger *}$ and Xavier Rovira ${ }^{\ddagger \dagger *}$

† MCS, Laboratory of Medicinal Chemistry, Institute for Advanced Chemistry of Catalonia (IQAC-CSIC), 08034, Barcelona, Spain.

$\S$ SIMchem, Service of Synthesis of High Added Value Molecules, Institute for Advanced Chemistry of Catalonia (IQAC-CSIC), 08034, Barcelona, Spain

¥ Molecular Photopharmacology Research Group, The Tissue Repair and Regeneration Laboratory (TR2Lab), Faculty of Sciences and Technology, University of Vic - Central University of Catalonia, 08500, Vic, Spain

\section{Supporting Information}

Table of Contents

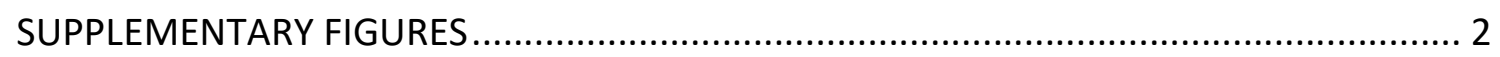

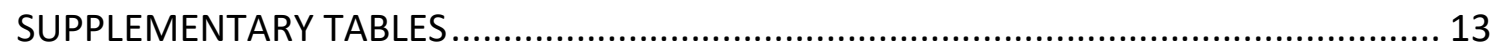

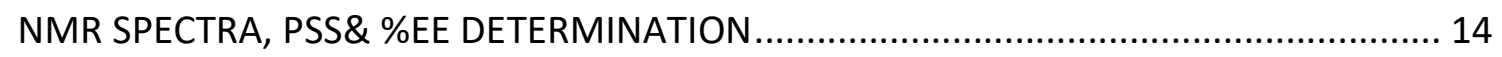




\section{SUPPLEMENTARY FIGURES}

A

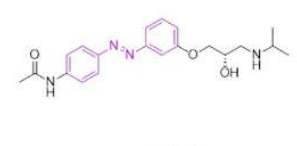

trans-PZL-2 $\stackrel{380 \mathrm{~nm}}{550 \mathrm{~nm}} \quad$ cis-PZL-2

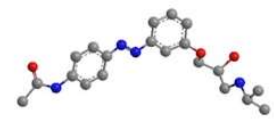

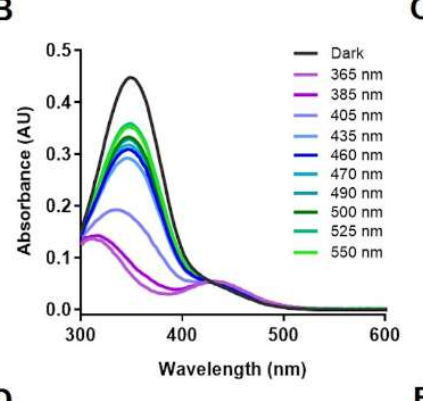

D

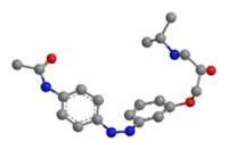

D

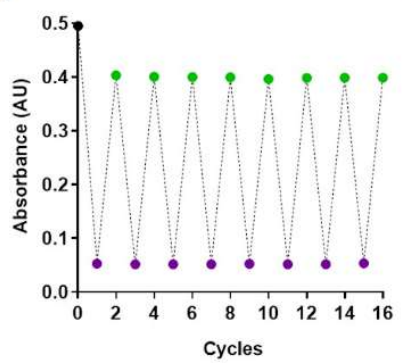

C

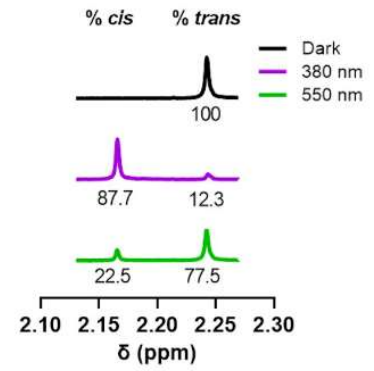

$E$

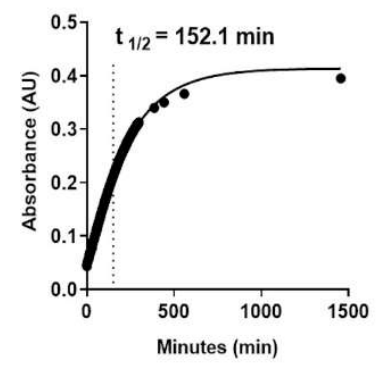

Figure S1. Photochemical characterization of Photoazolol-2 (PZL-2, $50 \mu \mathrm{M}$ in $\mathbf{0 . 5 \%}$ DMSO Buffer). (A) 2D and 3D chemical structures of the photoisomers of PZL-2. (B) UV-Vis spectra of the azobenzene under different light conditions. (C) Photostationary state (PSS) quantification by ${ }^{1} \mathrm{H}-\mathrm{NMR}$. (D) Multiple cis/trans isomerization cycles show the stability of the compound over 45 minutes of light application. (E) Half-lifetime estimation of cis-PZL-2 at $25{ }^{\circ} \mathrm{C}$; absorbance was measured at $364 \mathrm{~nm}$. 
A

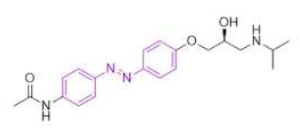

trans-PZL-3

$\frac{380 \mathrm{~nm}}{550 \mathrm{~nm}} \quad$ cis-PZL-3

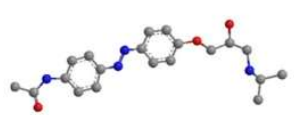

B

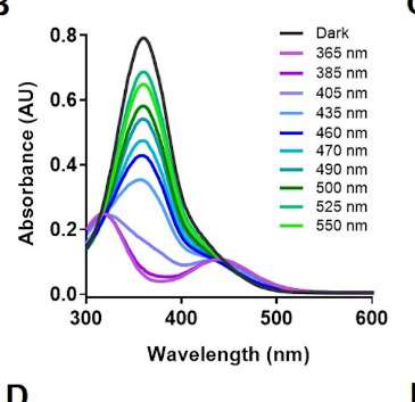

D

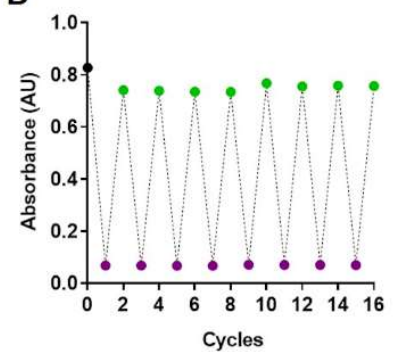

C

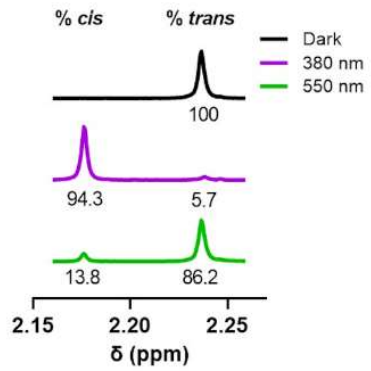

E

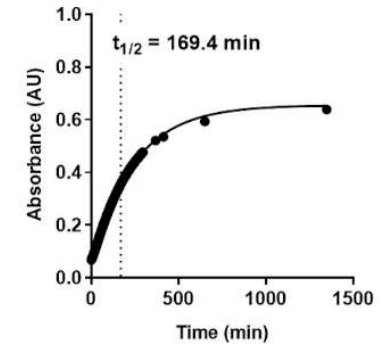

Figure S2. Photochemical characterization of Photoazolol-3 (PZL-3, $50 \mu \mathrm{M}$ in $\mathbf{0 . 5 \%}$ DMSO Buffer). (A) 2D and 3D chemical structures of the photoisomers of PZL-3. (B) UV-Vis spectra of the azobenzene under different light conditions. (C) Photostationary state (PSS) quantification by ${ }^{1} \mathrm{H}-\mathrm{NMR}$. (D) Multiple cis/trans isomerization cycles show the stability of the compound over 45 minutes of light application. (E) Half-lifetime estimation of cis-PZL-3 at $25{ }^{\circ} \mathrm{C}$; absorbance was measured at $364 \mathrm{~nm}$. 
Dark

$>95 \%$ trans-PZL-1

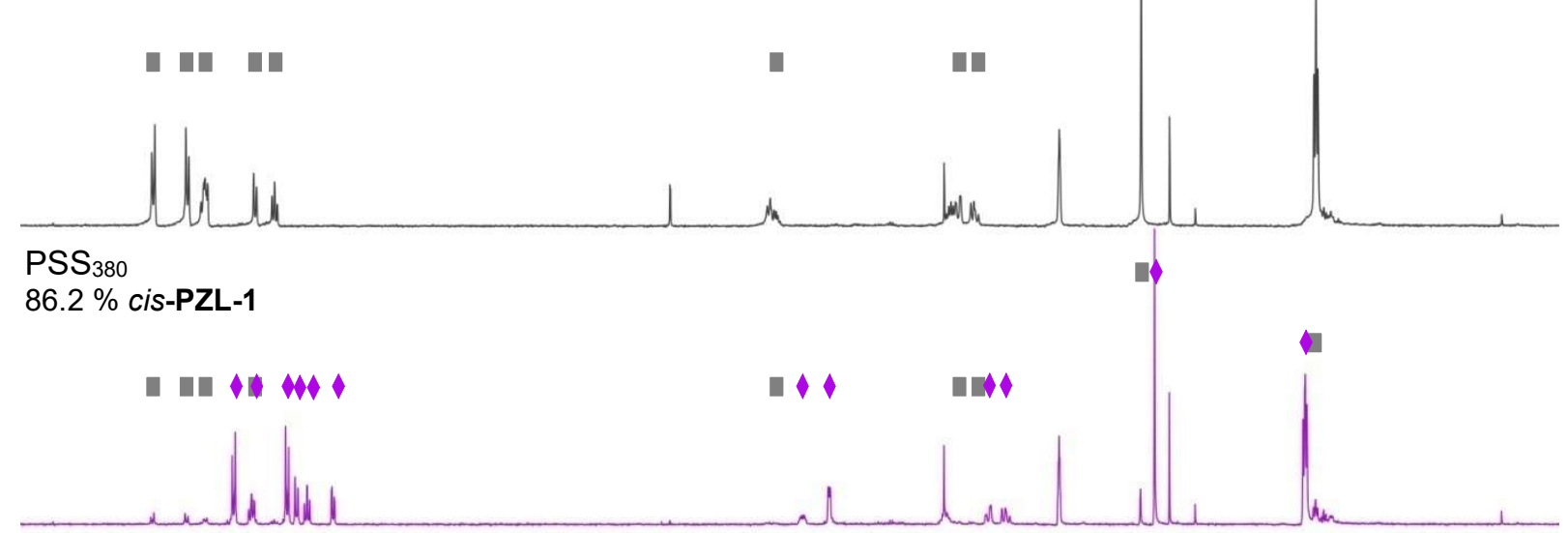

$\mathrm{PSS}_{550}$

$71.4 \%$ trans-PZL-1

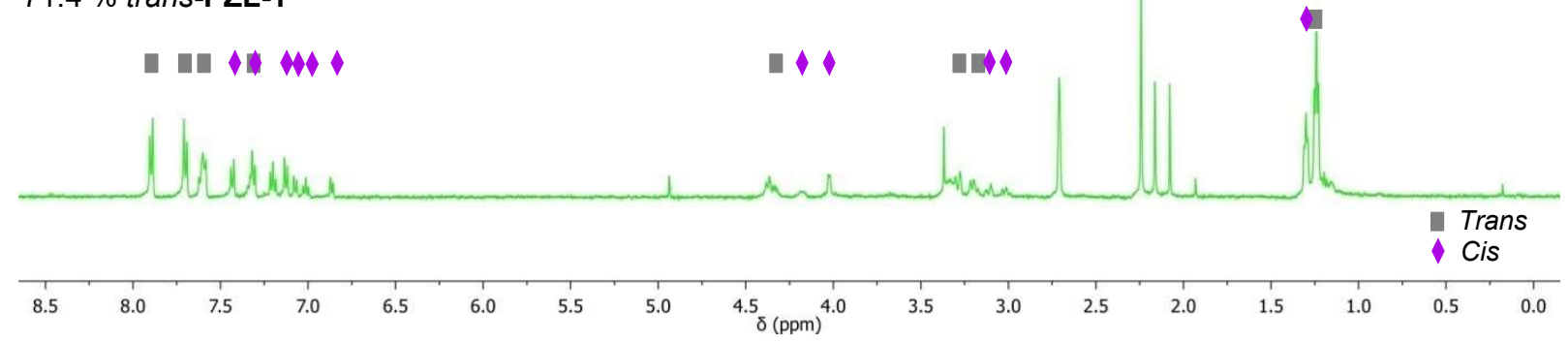

Figure S3. ${ }^{1} \mathrm{H}$ NMR studies of the photostationary states (PSS) of Photoazolol-1. A sample containing $0.1 \mathrm{mM}$ PZL-1 in $\mathrm{D}_{2} \mathrm{O}$ was analyzed in dark conditions and after illumination with $380 \mathrm{~nm}$ and $550 \mathrm{~nm}$ light sources. Grey squares illustrate the NMR signals corresponding to the trans isomer and the violet diamonds represent the cis signals. 

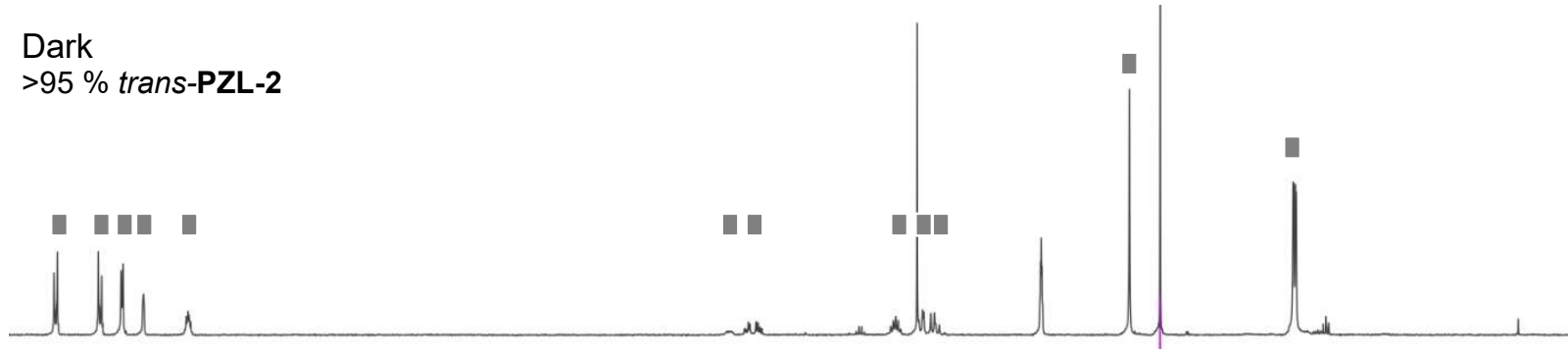

$\mathrm{PSS}_{380}$

$87.7 \%$ cis-PZL-2
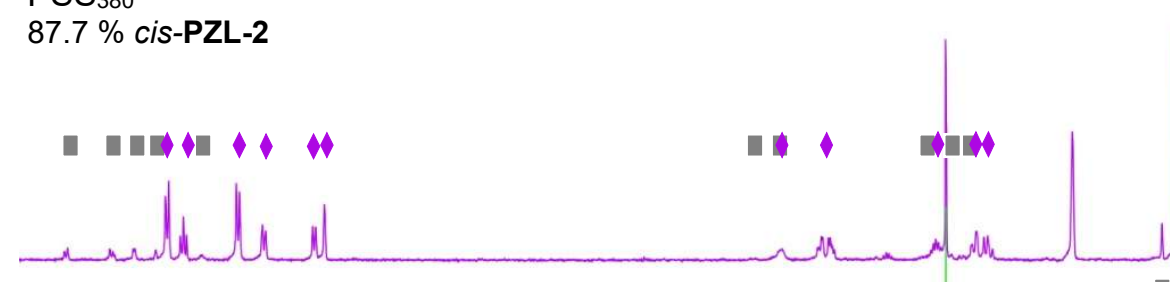

수

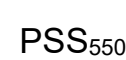

$77.5 \%$ trans-PZL-2

$\square+\Delta \bullet \bullet$

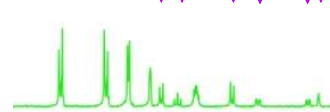

$\checkmark$

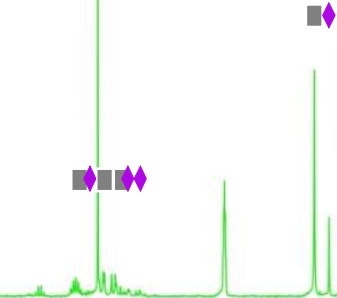

$\mathbf{B}$
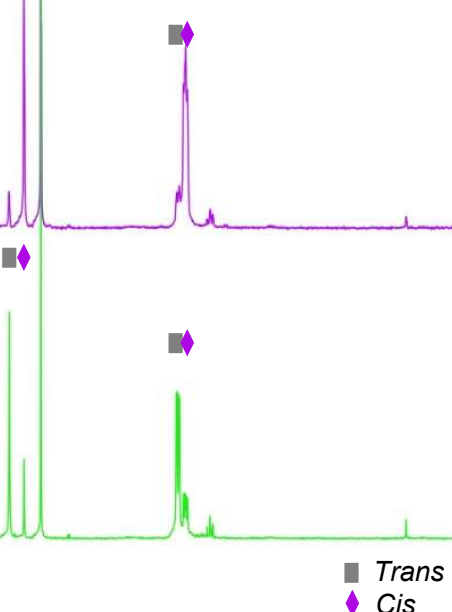

$8.0 \quad 7.5$

Figure S4. ${ }^{1} \mathrm{H}$ NMR studies of the photostationary states (PSS) of Photoazolol-2. A sample containing $0.1 \mathrm{mM}$ PZL-2 in $\mathrm{D}_{2} \mathrm{O}$ was analyzed in dark conditions and after illumination with $380 \mathrm{~nm}$ and $550 \mathrm{~nm}$ light sources. Grey squares illustrate the NMR signals corresponding to the trans isomer and the violet diamonds represent the cis signals. 


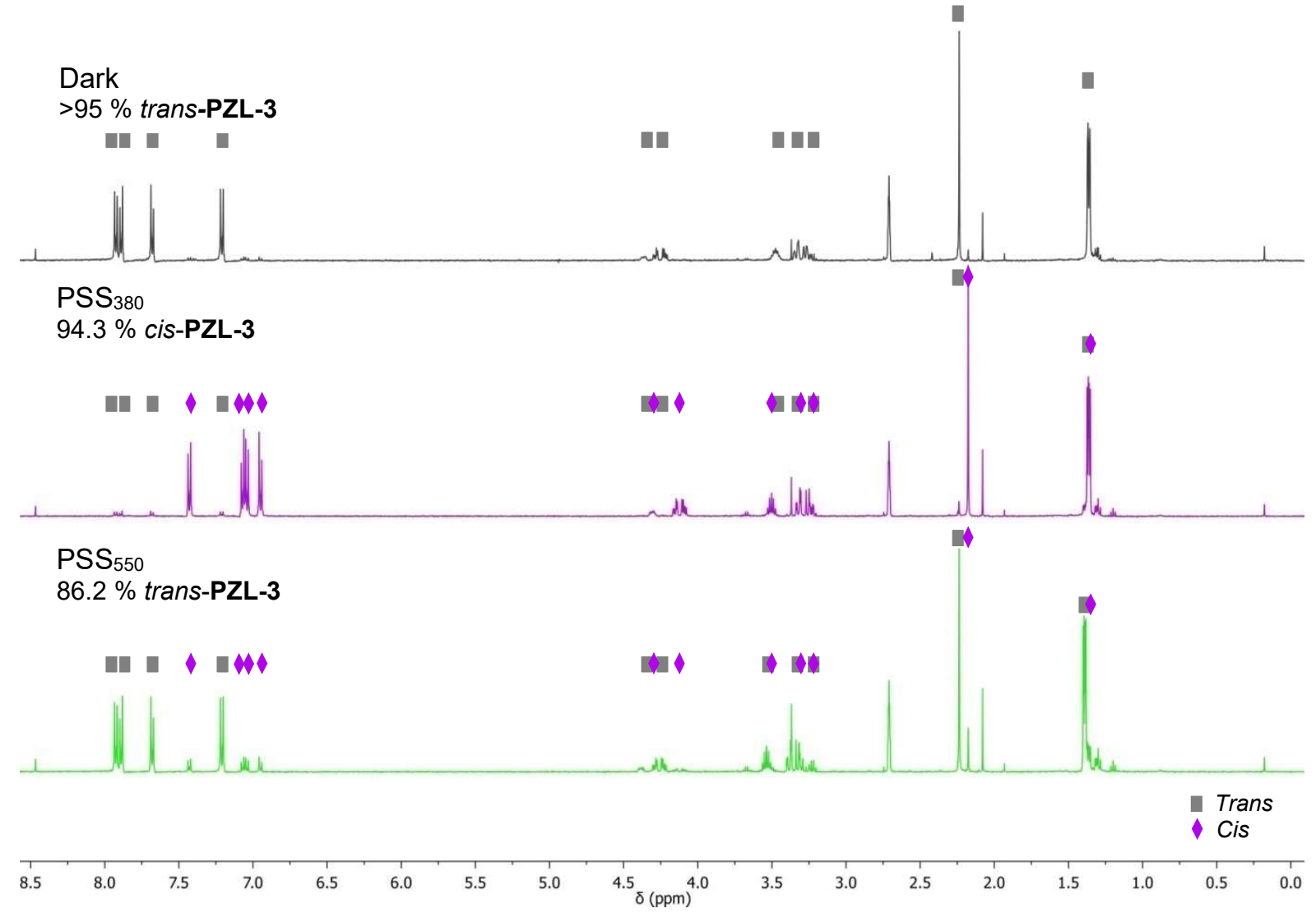

Figure S5. ${ }^{1} \mathrm{H}$ NMR studies of the photostationary states (PSS) of Photoazolol-3. A sample containing $0.1 \mathrm{mM}$ PZL-3 in $\mathrm{D}_{2} \mathrm{O}$ was analyzed in dark conditions and after illumination with $380 \mathrm{~nm}$ and $550 \mathrm{~nm}$ light sources. Grey squares illustrate the NMR signals corresponding to the trans isomer and the violet diamonds represent the cis signals. 
<smiles>CC(=O)Nc1ccc(N=Nc2ccc(OCC(O)CNC(C)C)cc2)cc1</smiles>

trans-PZL-3

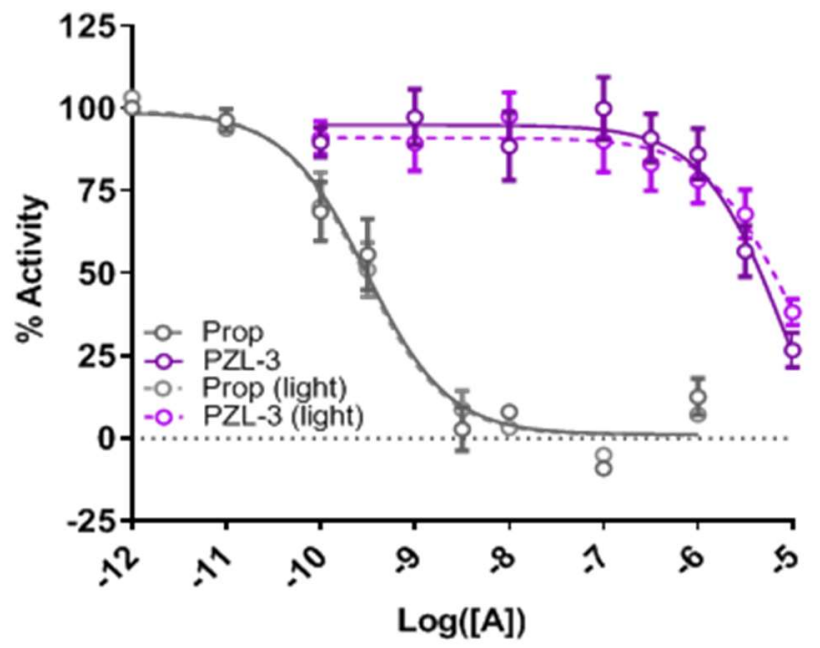

Figure S6. Dose-response curves of Photoazolol-3 with 3nM Cimaterol in the dark (continuous violet line) and under $380 \mathrm{~nm}$ light illumination (discontinuous light violet line). A dose-response of Propranolol (Prop) was tested in the same assay in dark (continuous grey line) and $380 \mathrm{~nm}$ light conditions (discontinuous light grey light). Data are shown as the mean \pm SEM of four independent experiments performed in duplicate.

A

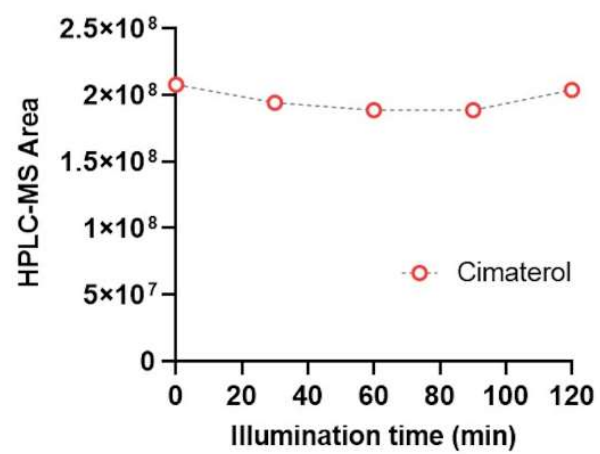

B

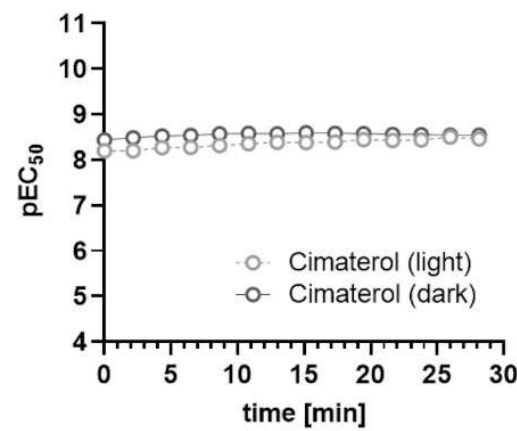

Figure S7. Chemical stability of $\boldsymbol{\beta}_{2}$-AR agonist cimaterol in aqueous media after light illumination. (A) $0.5 \mathrm{mg} / \mathrm{mL}$ solution of cimaterol (1\% DMSO in PBS) was continuously illumined with $405 \mathrm{~nm}$ light for different times (0-2h). The different samples were analyzed by HPLC-MS. (B) Cimaterol potency measured over $30 \mathrm{~min}$ and after 45 min incubation in the dark or under continuous illumination. 
A

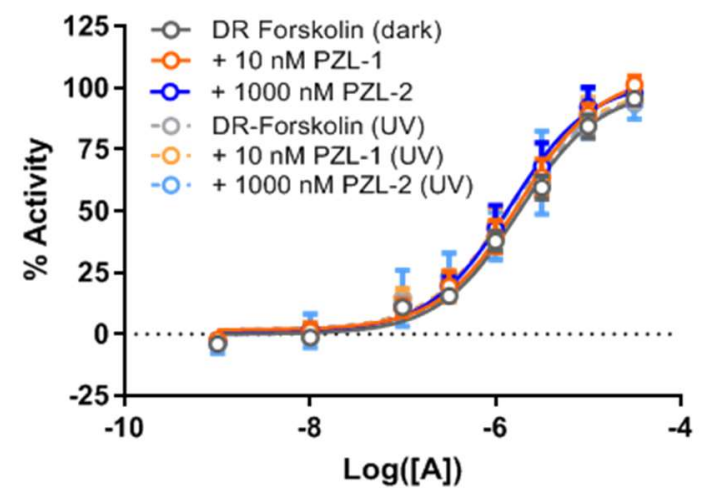

B

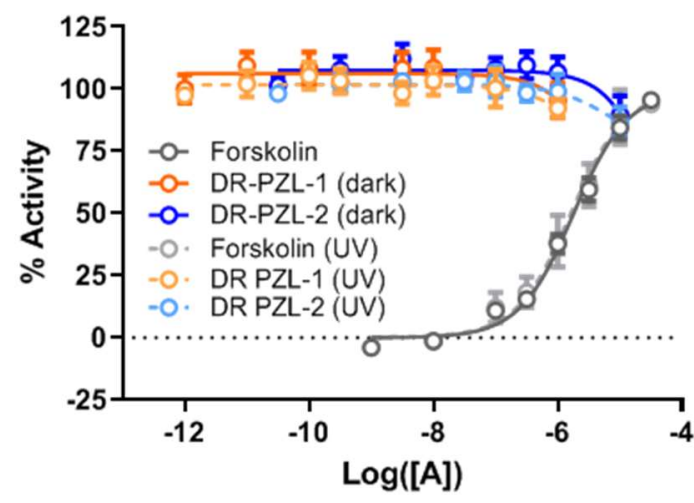

Figure S8. Validation of the effect of Photoazolol-1 and Photoazolol-2 on $\boldsymbol{\beta 2}$-AR. (A) Dose-response curves of forskolin with constant concentrations of PLZ-1 and PLZ$2(10 \mathrm{nM}$ and $1000 \mathrm{nM}$ respectively) in the dark (continuous lines) or under $380 \mathrm{~nm}$ light illumination (discontinuous lines). (B) Dose-response curves of PZL-1 and PZL-2 with $10 \mu \mathrm{M}$ forskolin in dark and $380 \mathrm{~nm}$ light conditions. Data are shown as the mean \pm SEM of three independent experiments performed in duplicate. 
A
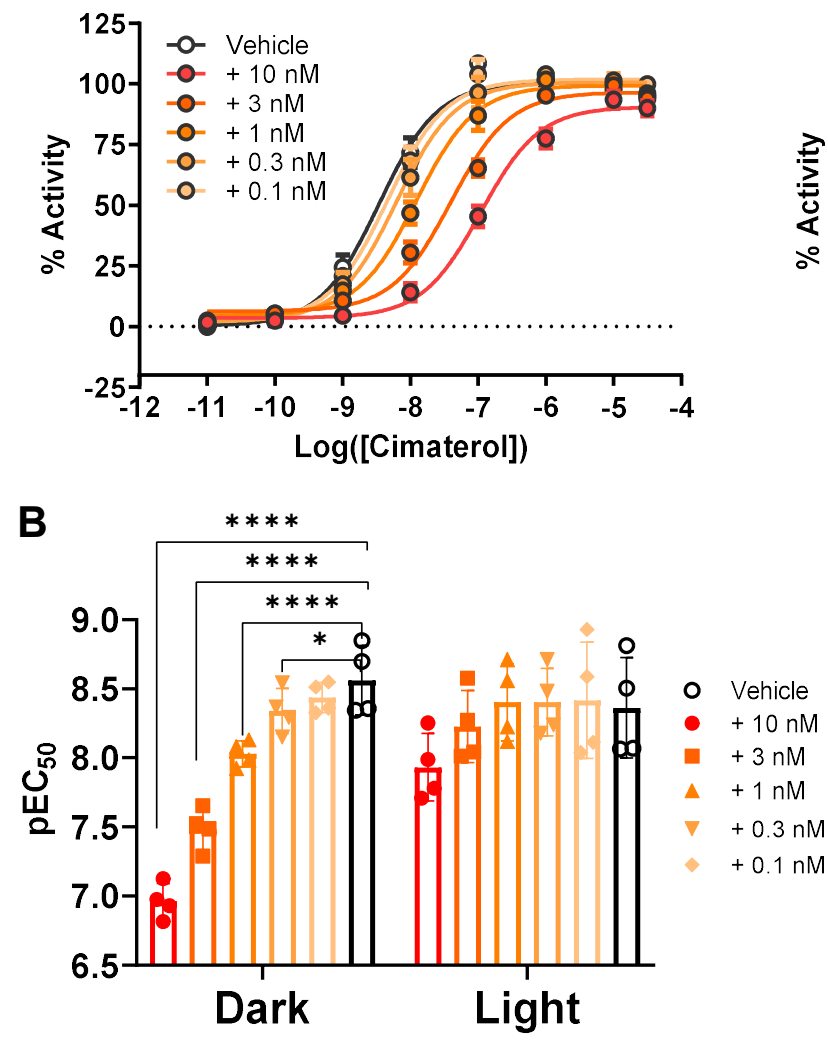

LIGHT

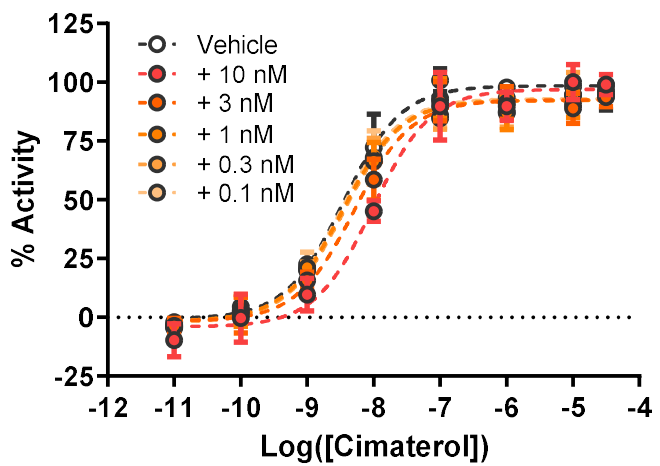

Figure S9. Antagonistic activity of Photoazolol-1. (A) Dose-response curves of cimaterol with different concentrations of PZL-1 under dark conditions or after $380 \mathrm{~nm}$ light illumination. (B) Representation of the $\mathrm{pEC}_{50}$ values obtained on the different replicates on panel A. Each data point represents the mean and SEM of four experiments performed in duplicate. Statistical differences from light $\mathrm{EC}_{50}$ values are denoted for adjusted $p$ values as follows: ${ }^{*} p<0.05$ and ${ }^{* * * *} p<0.0001$. 
A
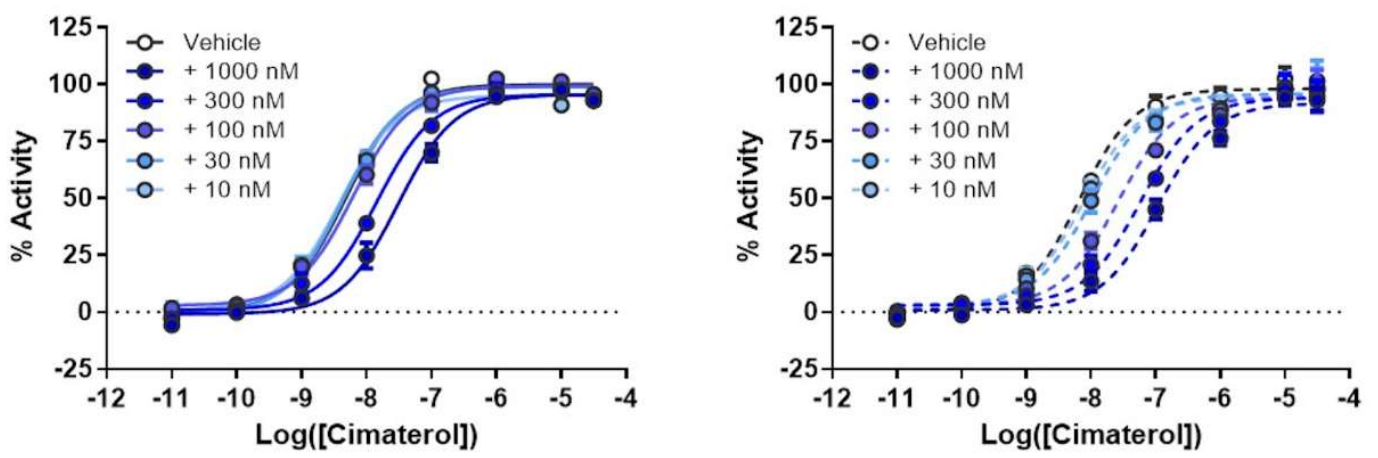

B

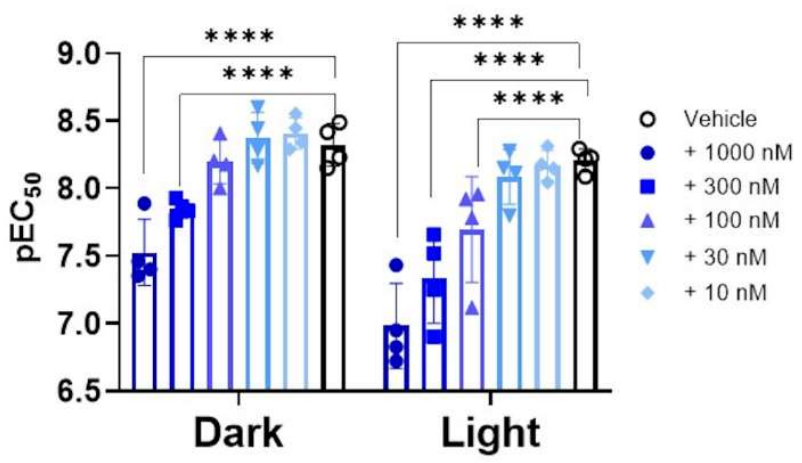

Figure S10. Antagonistic activity of Photoazolol-2. (A) Dose-response curves of cimaterol with different concentrations of PZL-2 under dark conditions or after $380 \mathrm{~nm}$ light illumination. (B) Representation of the $\mathrm{pEC}_{50}$ values obtained on the different replicates on panel $A$. Each data point represents the mean and SEM of four experiments performed in duplicate. Statistical differences are denoted for adjusted $p$ values as follows: ${ }^{* * * *} p<0.0001$. 
A

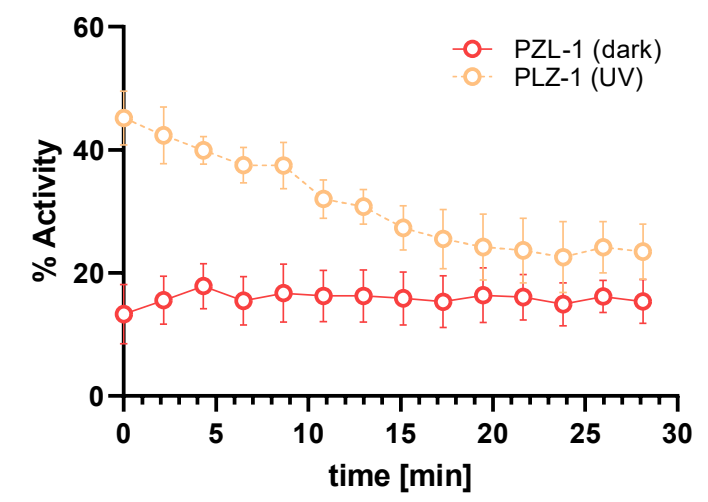

B

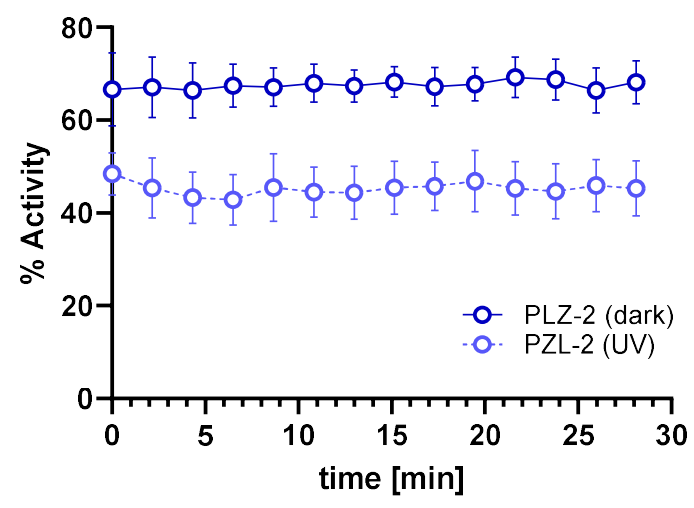

Figure S11. Time evolution of receptor activation state in cells treated with Photoazolol-1 and Photoazolol-2 in the dark and under illumination. In vitro intracellular cAMP was continuously monitored in the dark for $30 \mathrm{~min}$ after a $45 \mathrm{~min}$ pre-incubation with the azobenzenes in the dark or under $380 \mathrm{~nm}$ light illumination. (A) Cells treated with $10 \mathrm{nM}$ PZL-1 and $10 \mathrm{nM}$ of the agonist cimaterol. (B) Cells treated with $1 \mu \mathrm{M}$ PZL-2 and $100 \mathrm{nM}$ of the agonist cimaterol. Each data point represents the mean and SEM of three experiments performed in duplicate.

A

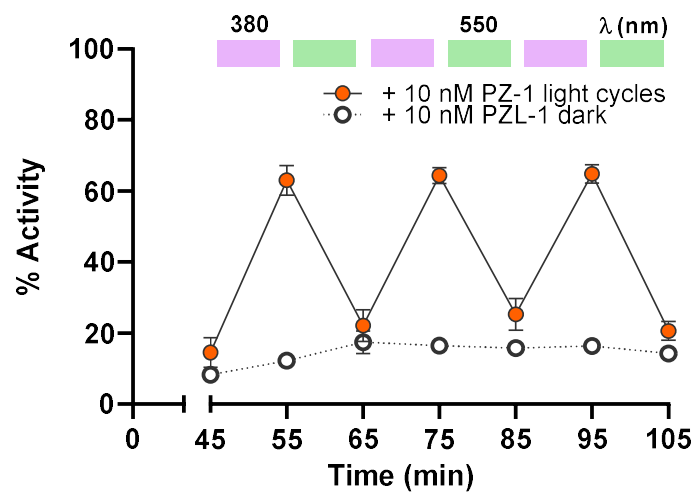

B

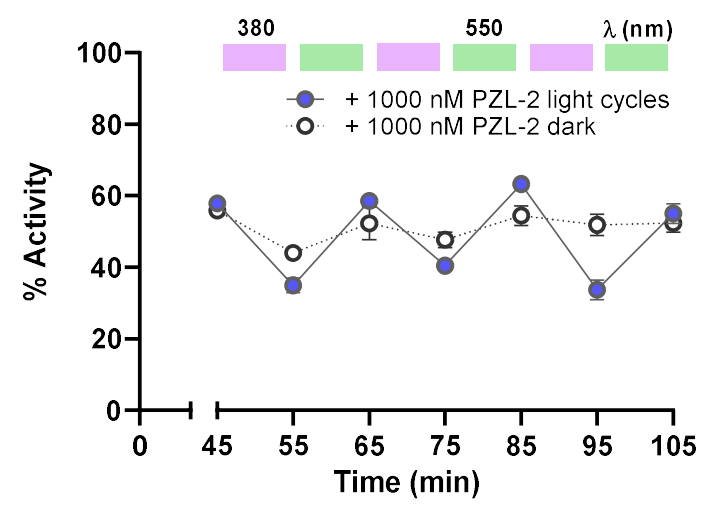

Figure S12. Real-time optical control of $\boldsymbol{\beta}_{2}$-AR. Time course quantification of intracellular cAMP challenged with the $\beta_{2}-A R$ agonist cimaterol $(10 \mathrm{nM}$ and $100 \mathrm{nM}$, respectively) in the presence of PZL-1 (A) or PZL-2 (B). Violet and green boxes correspond to 10 min illumination breaks using $380 \mathrm{~nm}$ and $550 \mathrm{~nm}$ lights, respectively. PZL-1 and PLZ-2 in dark conditions are represented by white dots. Each data point represents the mean and SEM of three to four experiments performed in duplicate. 

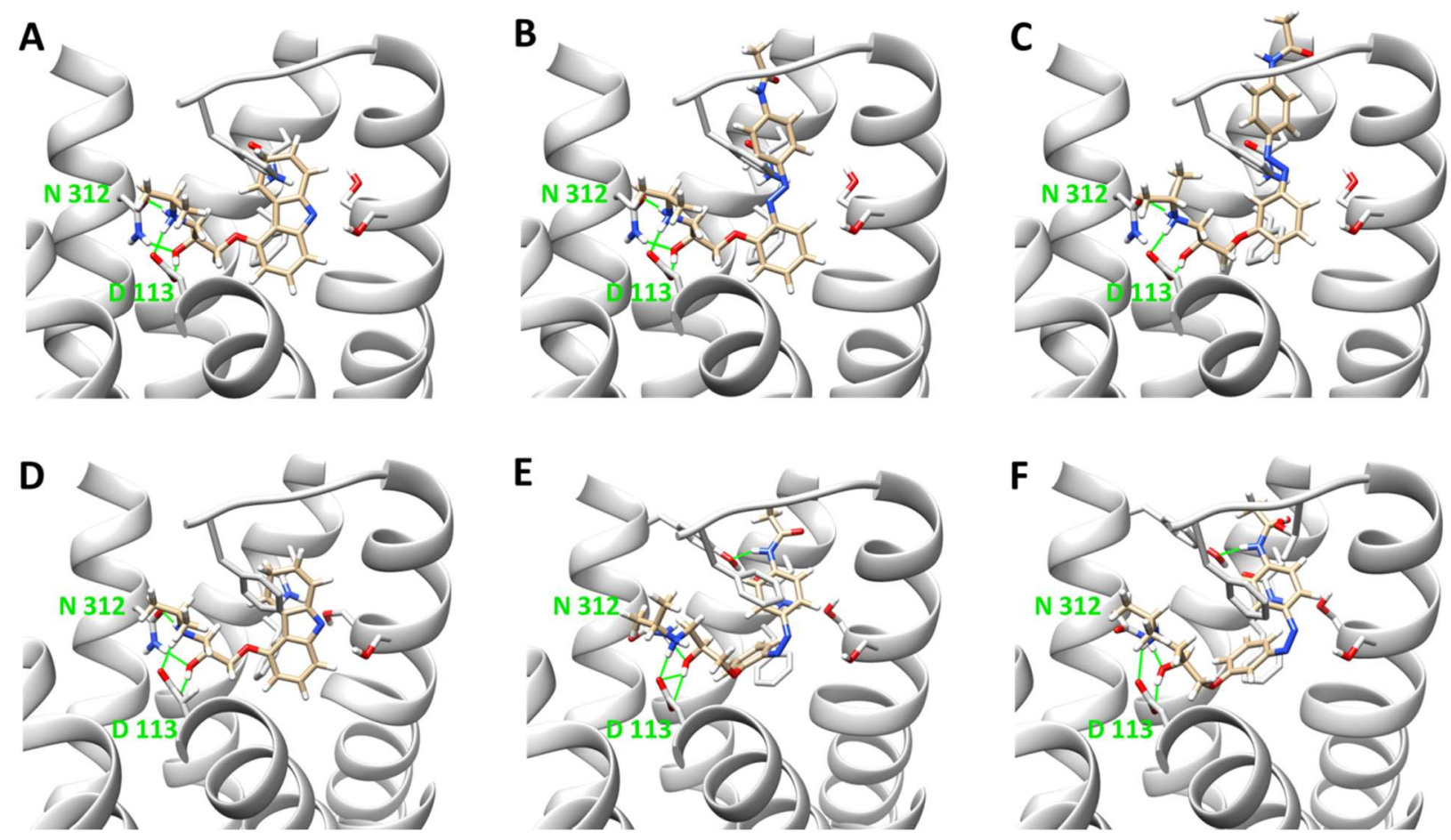

Figure S13. (A-C) Rigid docking results for carazolol, PZL-1 in trans configuration and PZL-2 in trans configuration, respectively. (D-E) Induced fit results for carazolol, PZL-1 and PZL-2, both in cis configuration. 


\section{SUPPLEMENTARY TABLES}

Table S1. $E_{50}$ values of cimaterol Dose-Response curves with different concentrations of Photoazolol-1 under different light conditions (Figure S9).

\begin{tabular}{c:cc:cc} 
& \multicolumn{2}{c}{ DARK } & \multicolumn{2}{c}{ LIGHT } \\
\hline Conditions & EC $_{50}(\mathrm{nM})$ & SEM & $\mathrm{EC}_{50}(\mathrm{nM})$ & SEM \\
\hline No PZL-1 & 3.08 & 0.80 & 5.44 & 1.83 \\
$+0.1 \mathrm{nM}$ & 3.74 & 0.46 & 5.15 & 1.93 \\
$+0.3 \mathrm{nM}$ & 4.81 & 0.88 & 4.40 & 1.08 \\
$+1 \mathrm{nM}$ & $9.49^{* * *}$ & 1.01 & 4.57 & 1.34 \\
$+3 \mathrm{nM}$ & $34.01^{* * *}$ & 6.21 & 6.68 & 1.65 \\
$+10 \mathrm{nM}$ & $112.68^{* * *}$ & 16.09 & 12.97 & 3.12
\end{tabular}

Statistical differences between dark and light $\mathrm{EC}_{50}$ values for each concentration were analyzed through an extra sum-of-squares $F$ test for adjusted $p$ values as follows: ${ }^{* * *} p<0.001$ and ${ }^{* * * *} \mathrm{p}<0.0001$.

Table S2. $E_{50}$ values of cimaterol Dose-Response curves with variable concentrations of Photoazolol-2 under different light conditions (Figure S10).

\begin{tabular}{c:cc:cc} 
& \multicolumn{2}{c}{ DARK } & \multicolumn{2}{c}{ LIGHT } \\
\hline Conditions & EC $_{50}(\mathrm{nM})$ & SEM & EC $_{50}(\mathrm{nM})$ & SEM \\
\hline No PZL-2 & 5.00 & 0.88 & 6.30 & 0.65 \\
$+10 \mathrm{nM}$ & $4.01^{*}$ & 0.52 & 6.92 & 0.86 \\
$+30 \mathrm{nM}$ & $4.53^{* *}$ & 0.94 & 8.98 & 2.35 \\
$+100 \mathrm{nM}$ & $6.67^{* * *}$ & 1.23 & 28.95 & 15.83 \\
$+300 \mathrm{nM}$ & $14.35^{\star * * *}$ & 1.12 & 58.22 & 23.34 \\
$+1000 \mathrm{nM}$ & $32.88^{* * * *}$ & 6.94 & 122.22 & 32.51
\end{tabular}

Statistical differences between dark and light $\mathrm{EC}_{50}$ values for each concentration were analyzed through an extra sum-of-squares $F$ test for adjusted $p$ values as follows: ${ }^{*} p<0.05$, ${ }^{* *} p<0.01$, ${ }^{* * * *} p<0.0001$. 
NMR SPECTRA, PSS\& \%EE DETERMINATION

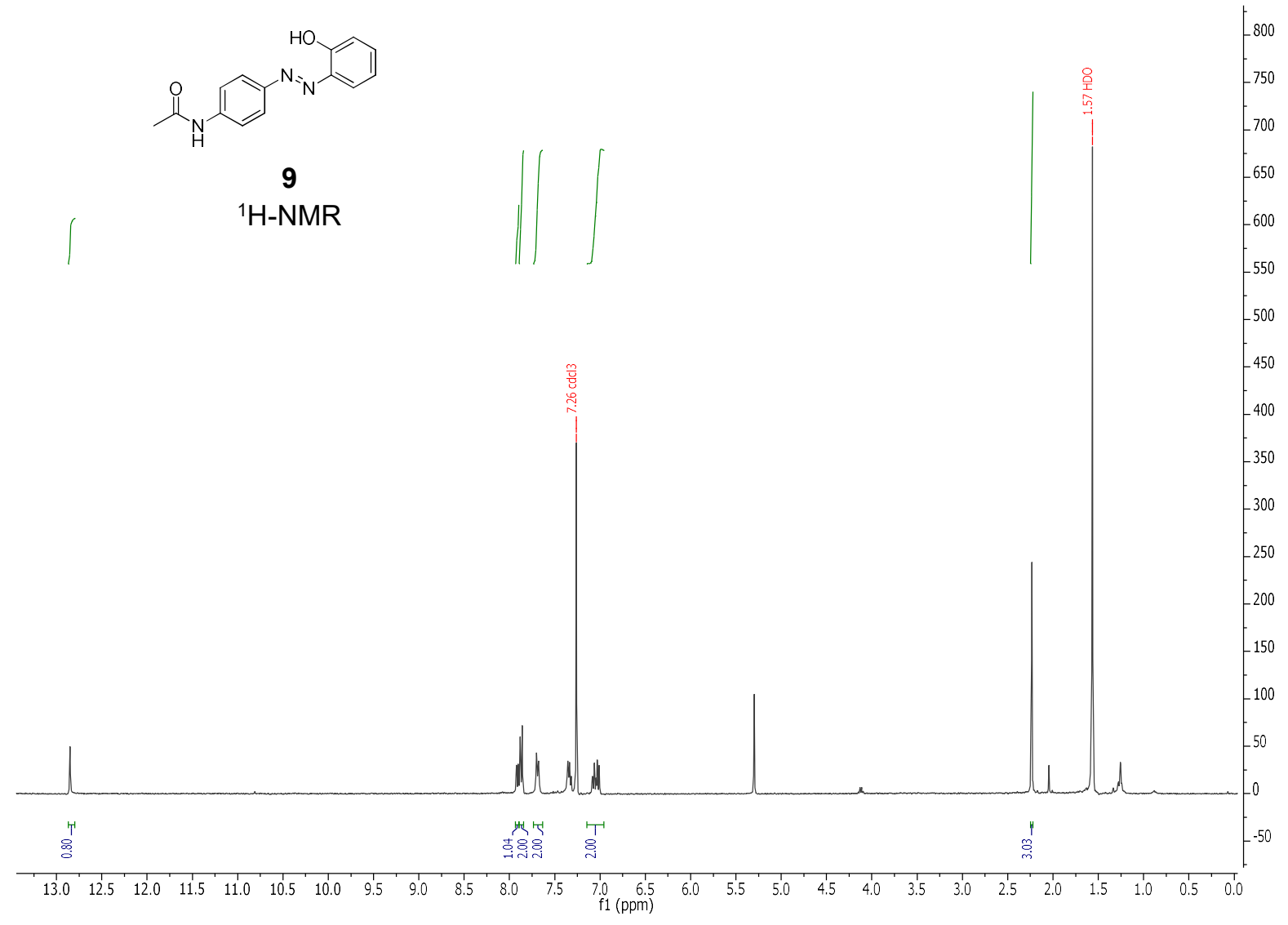

S14 

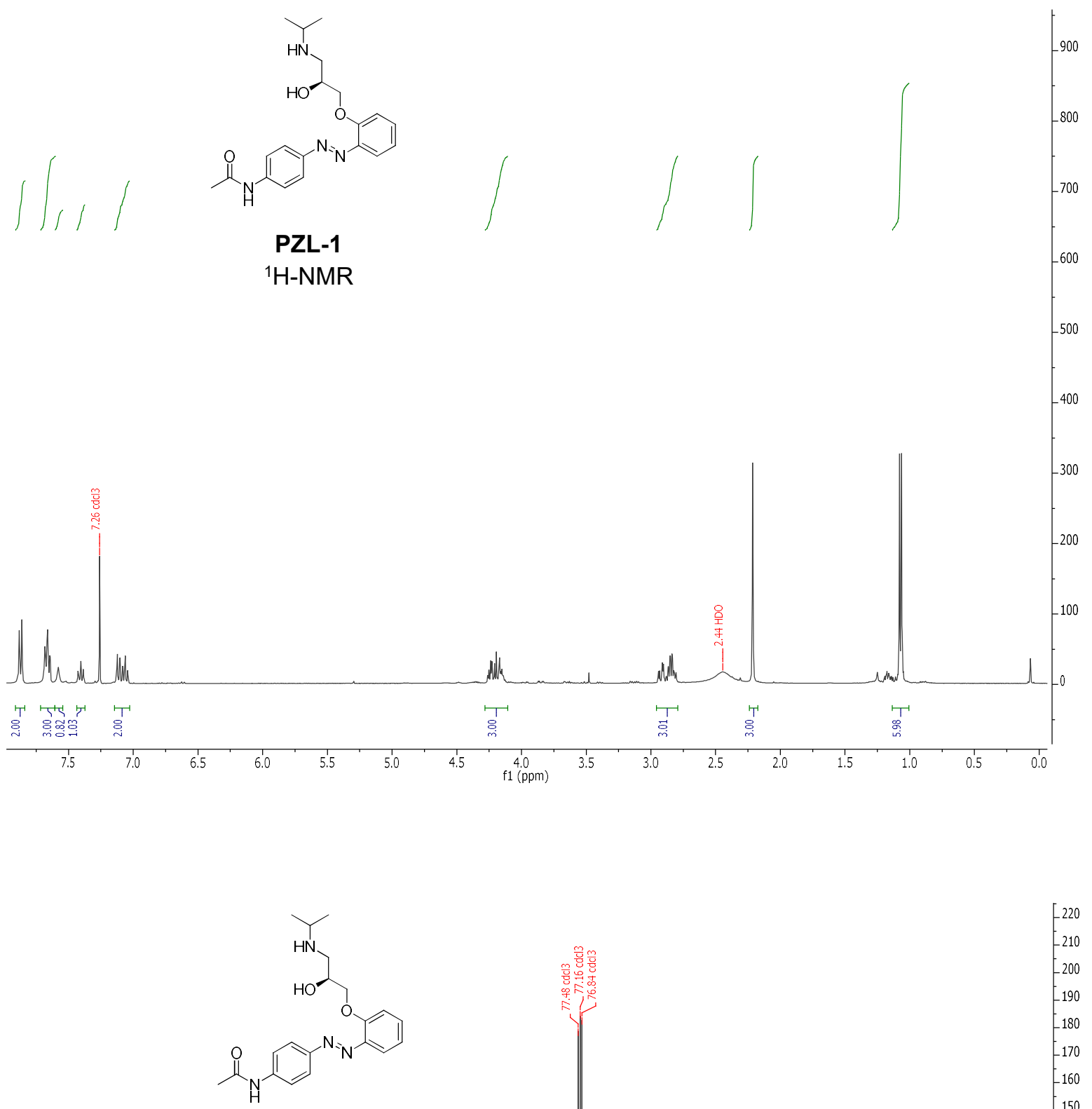

PZL-1

${ }^{13} \mathrm{C}-\mathrm{NMR}$

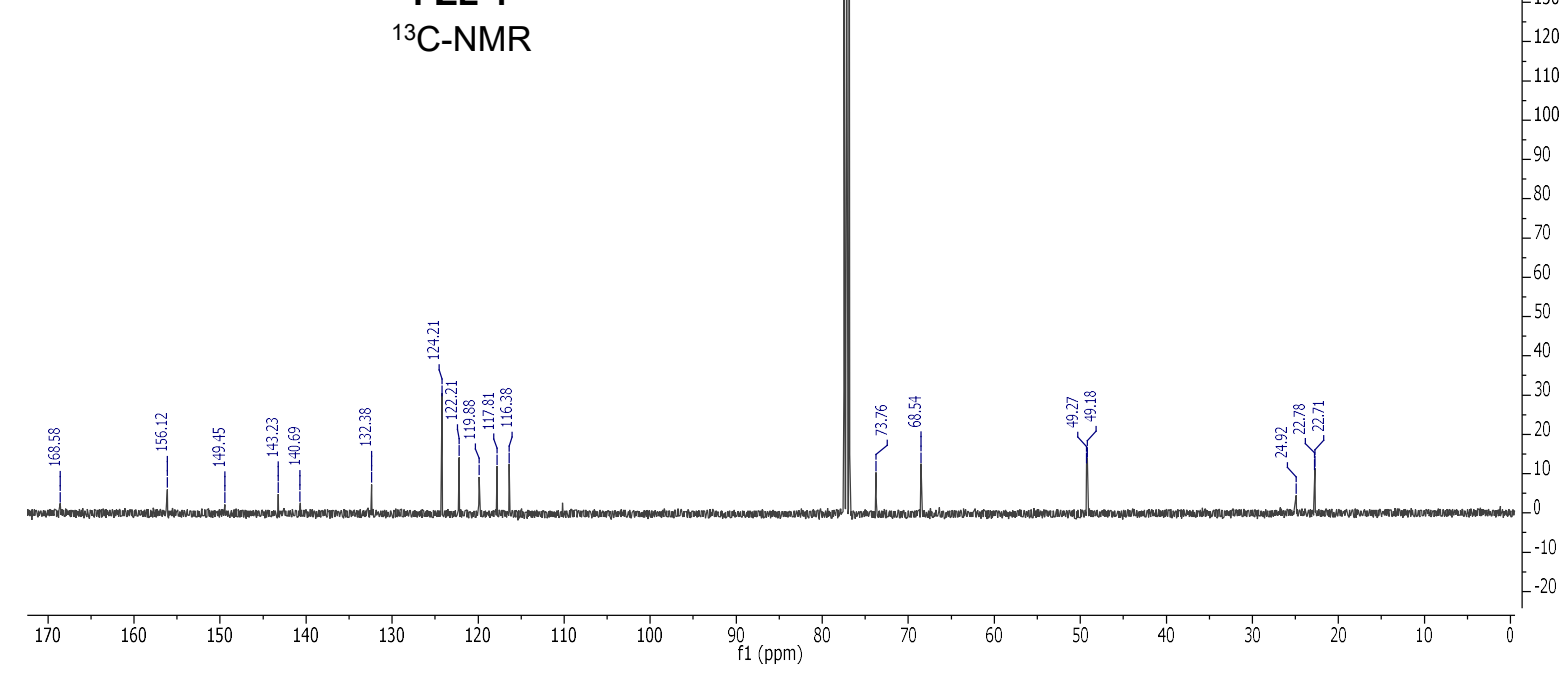



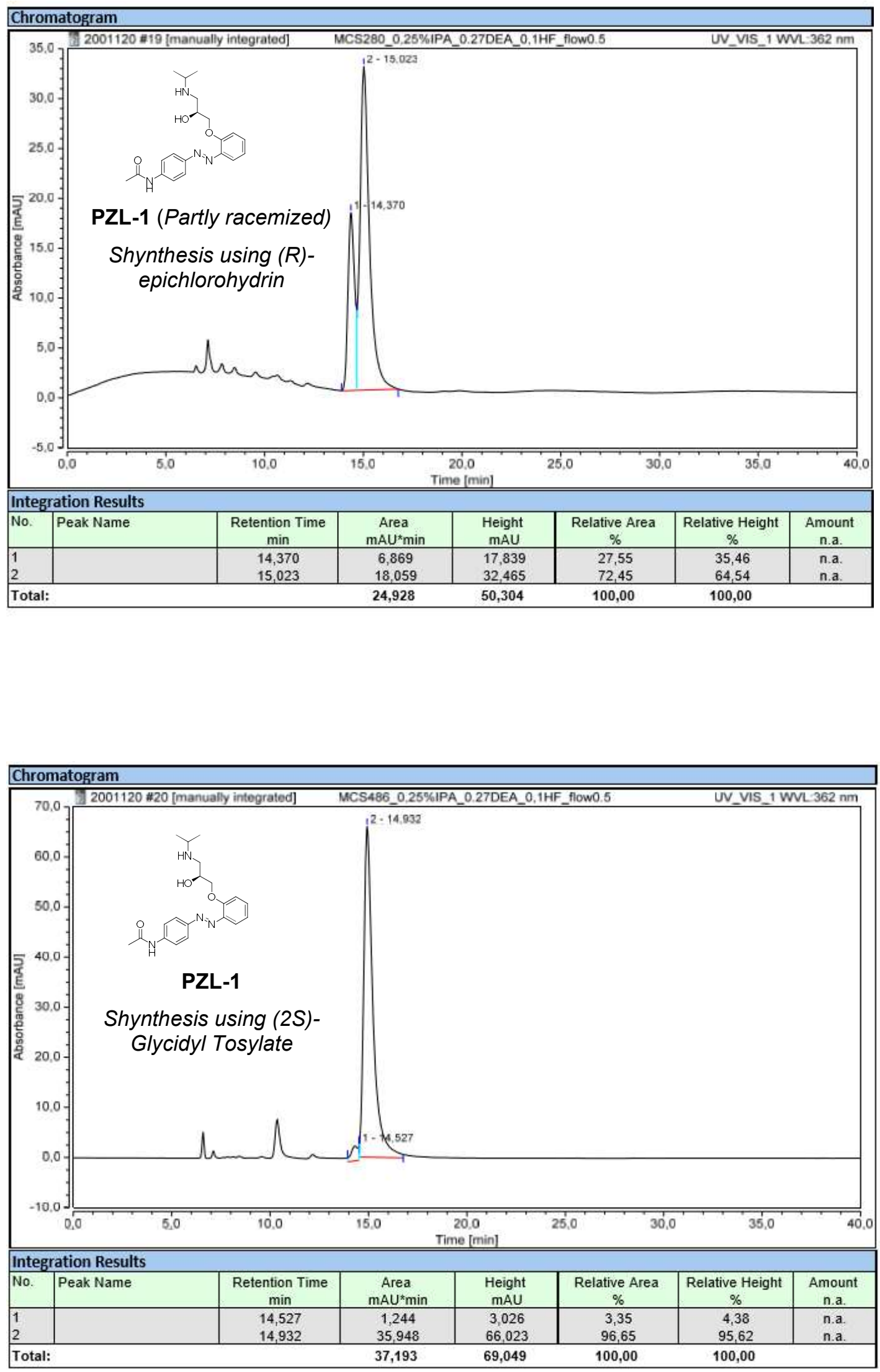


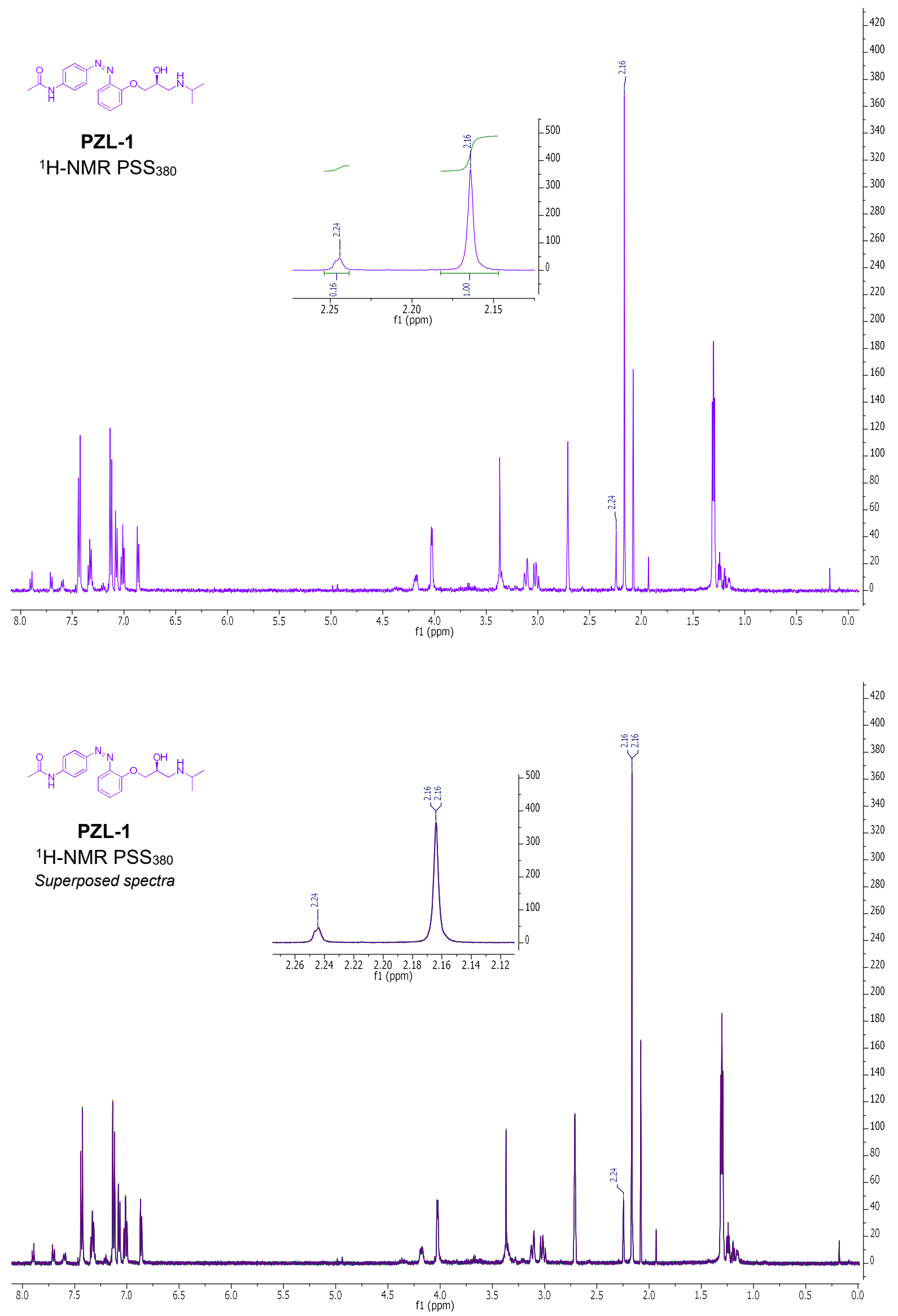



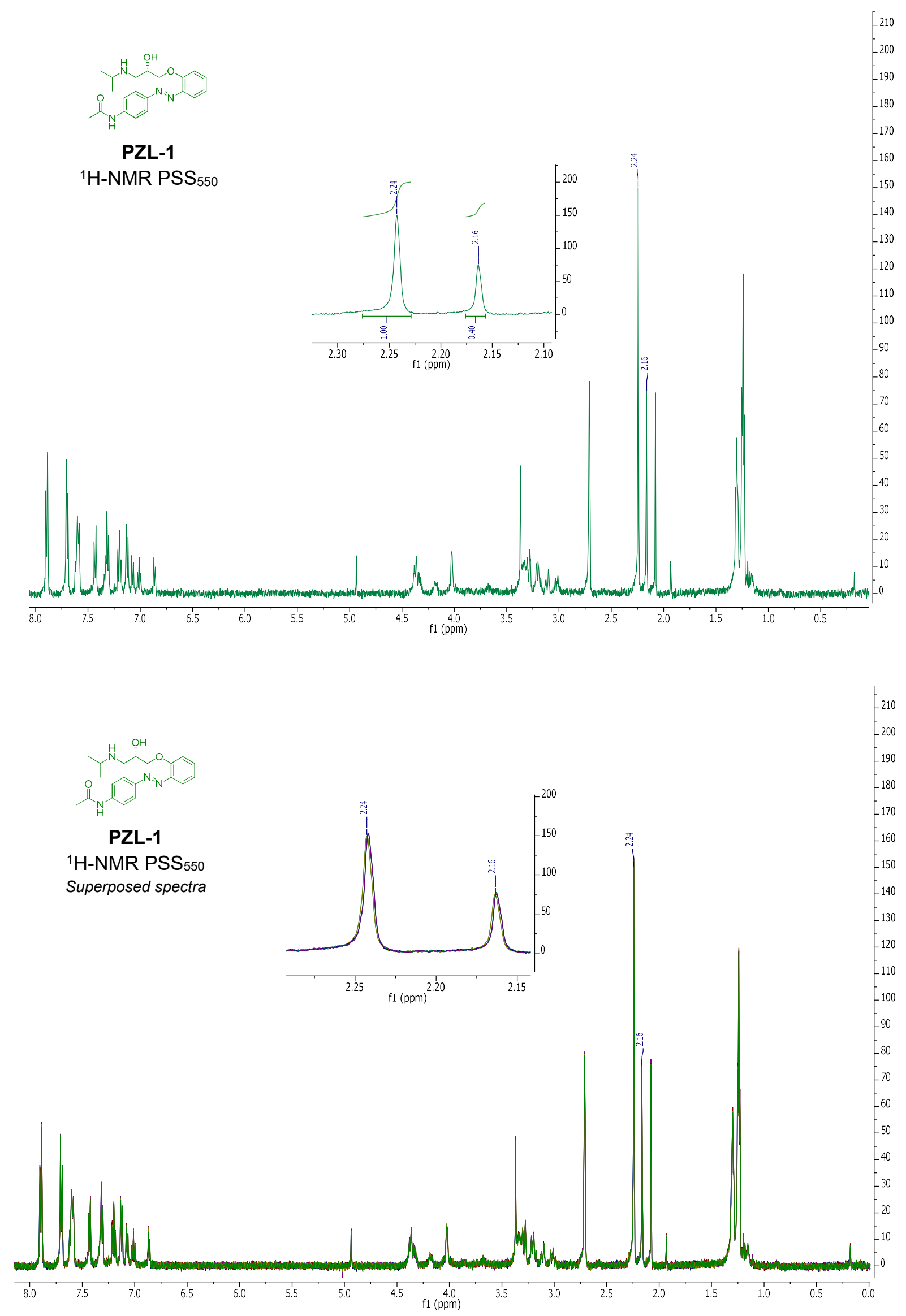

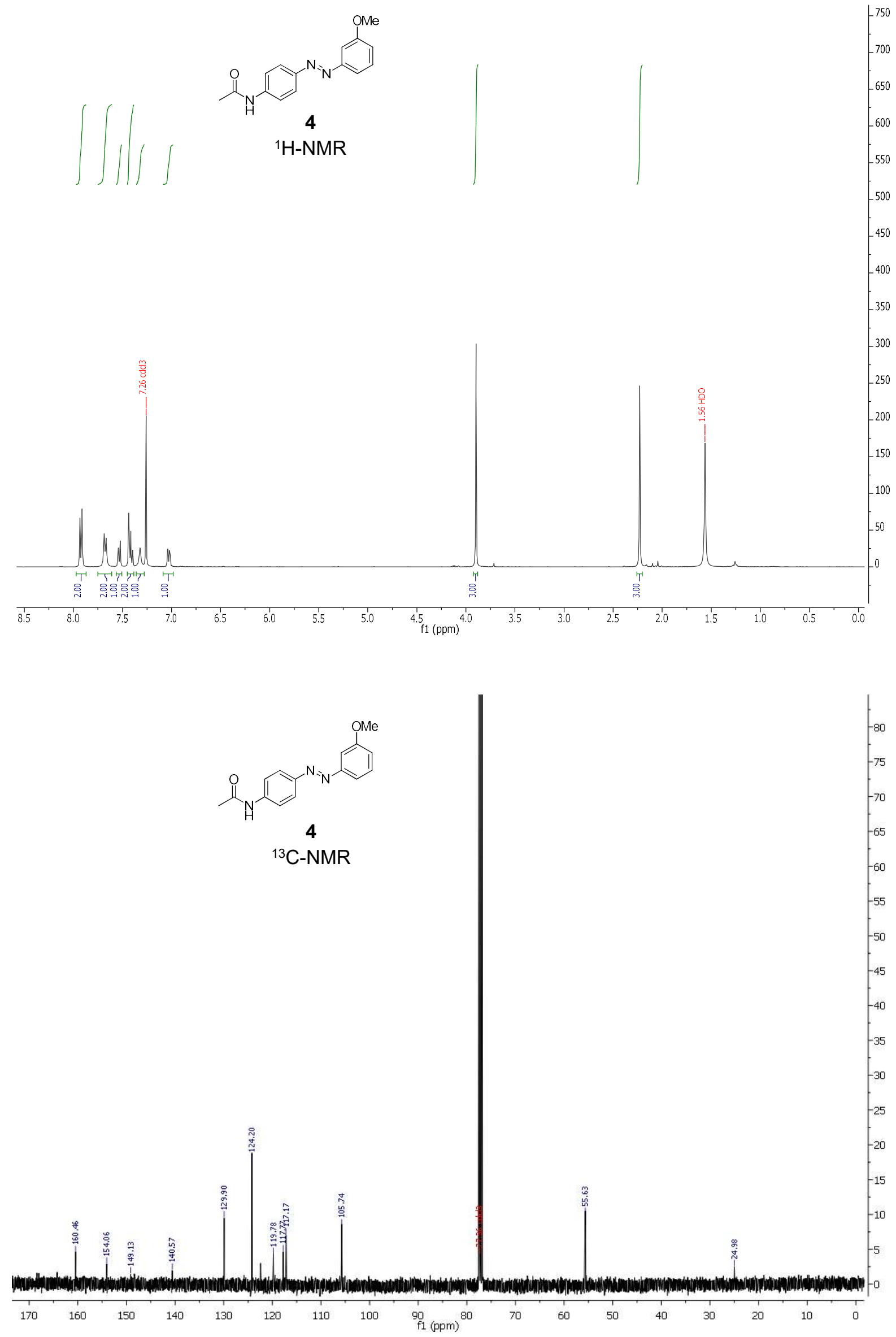


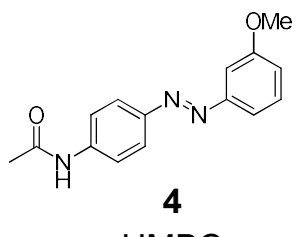

(udd) It

HMBC

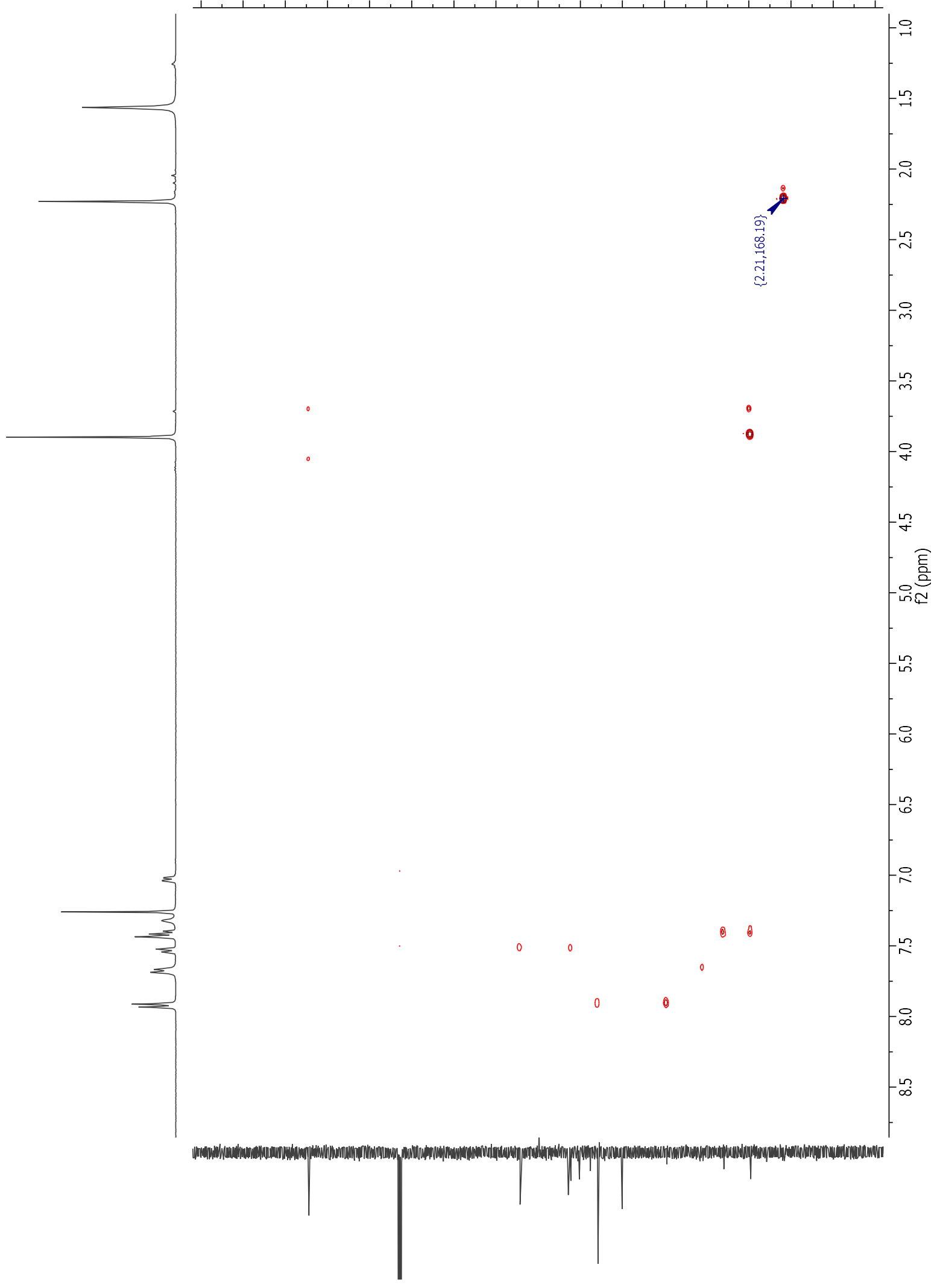



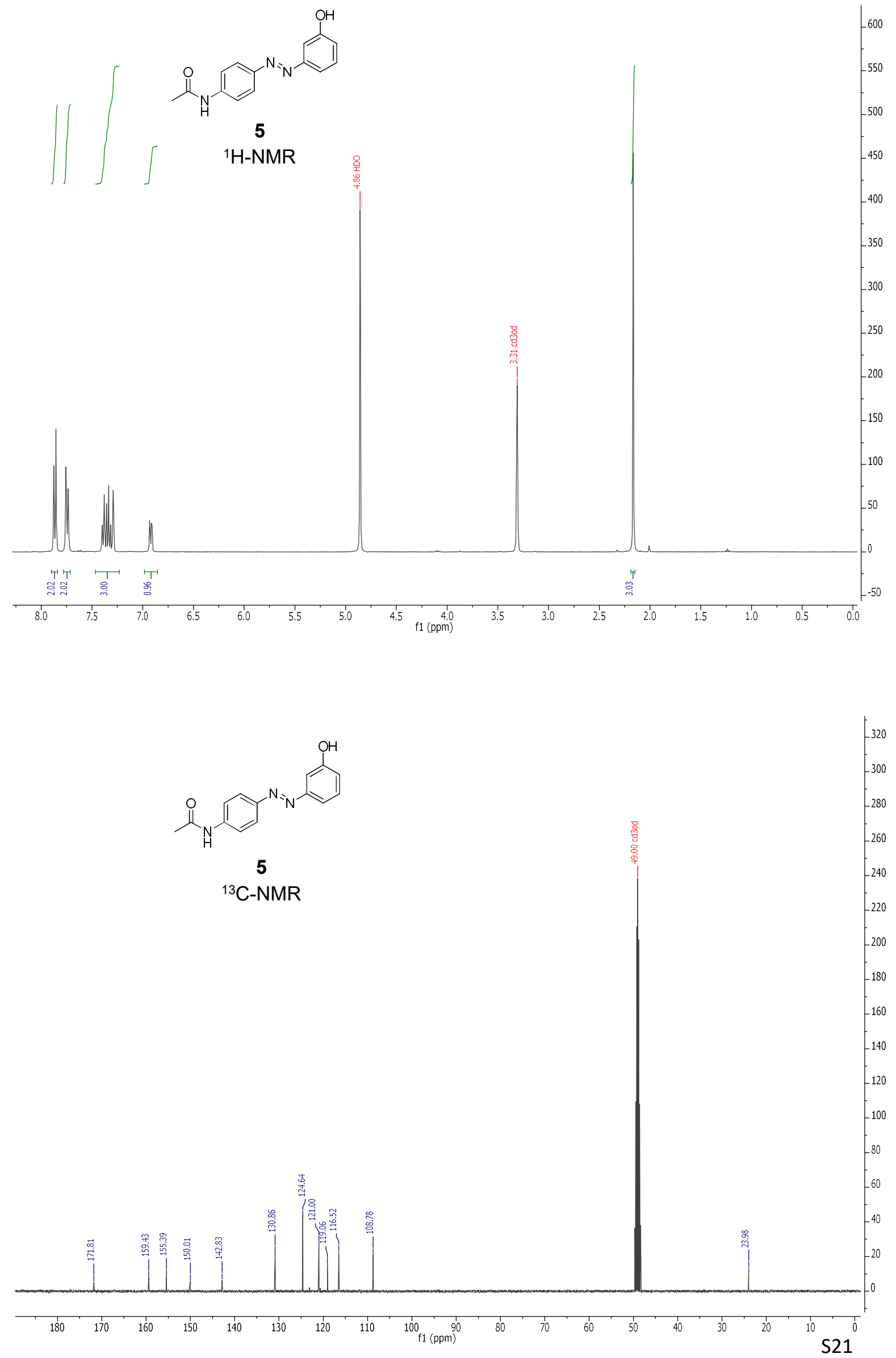

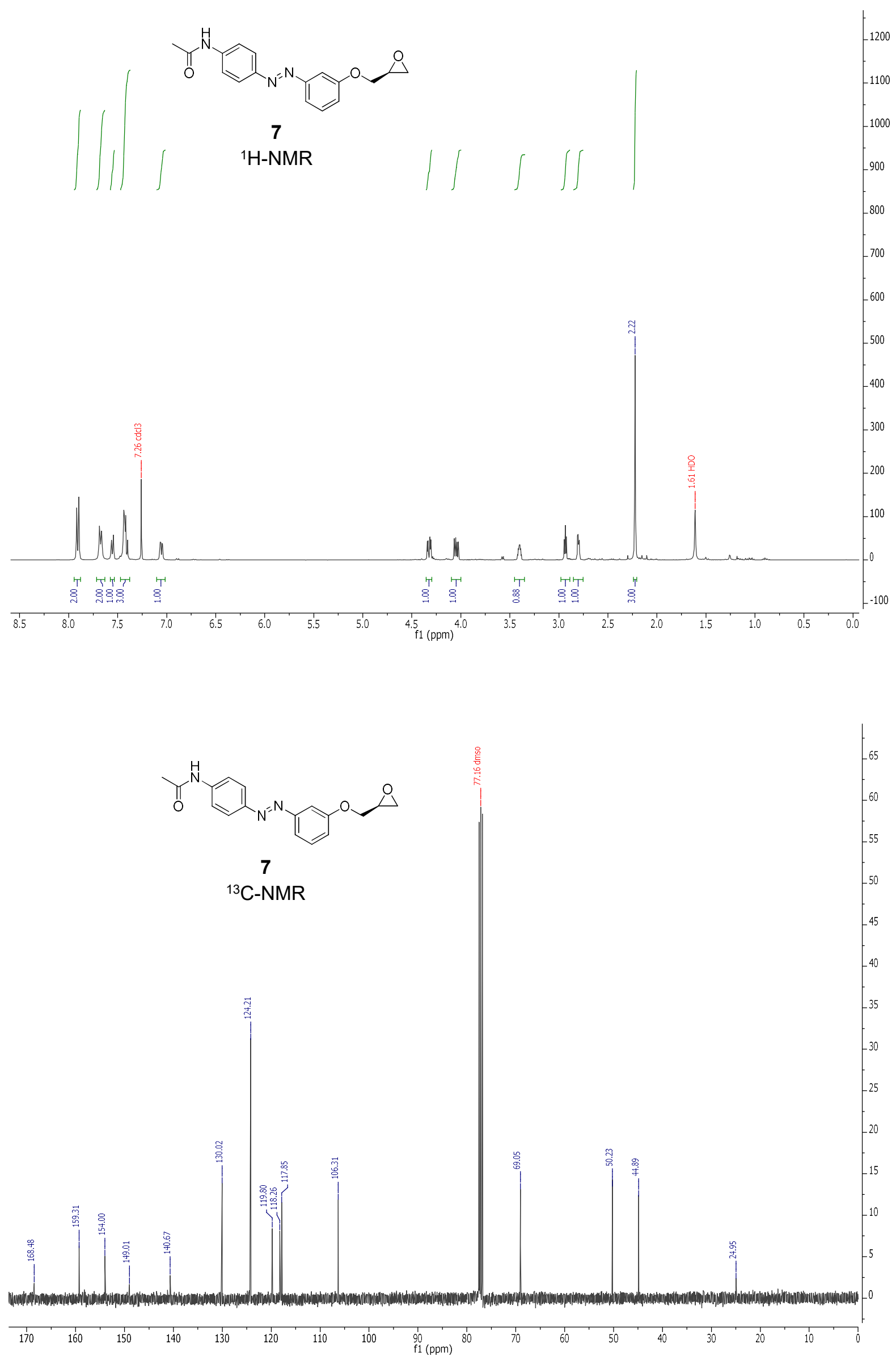

S22 

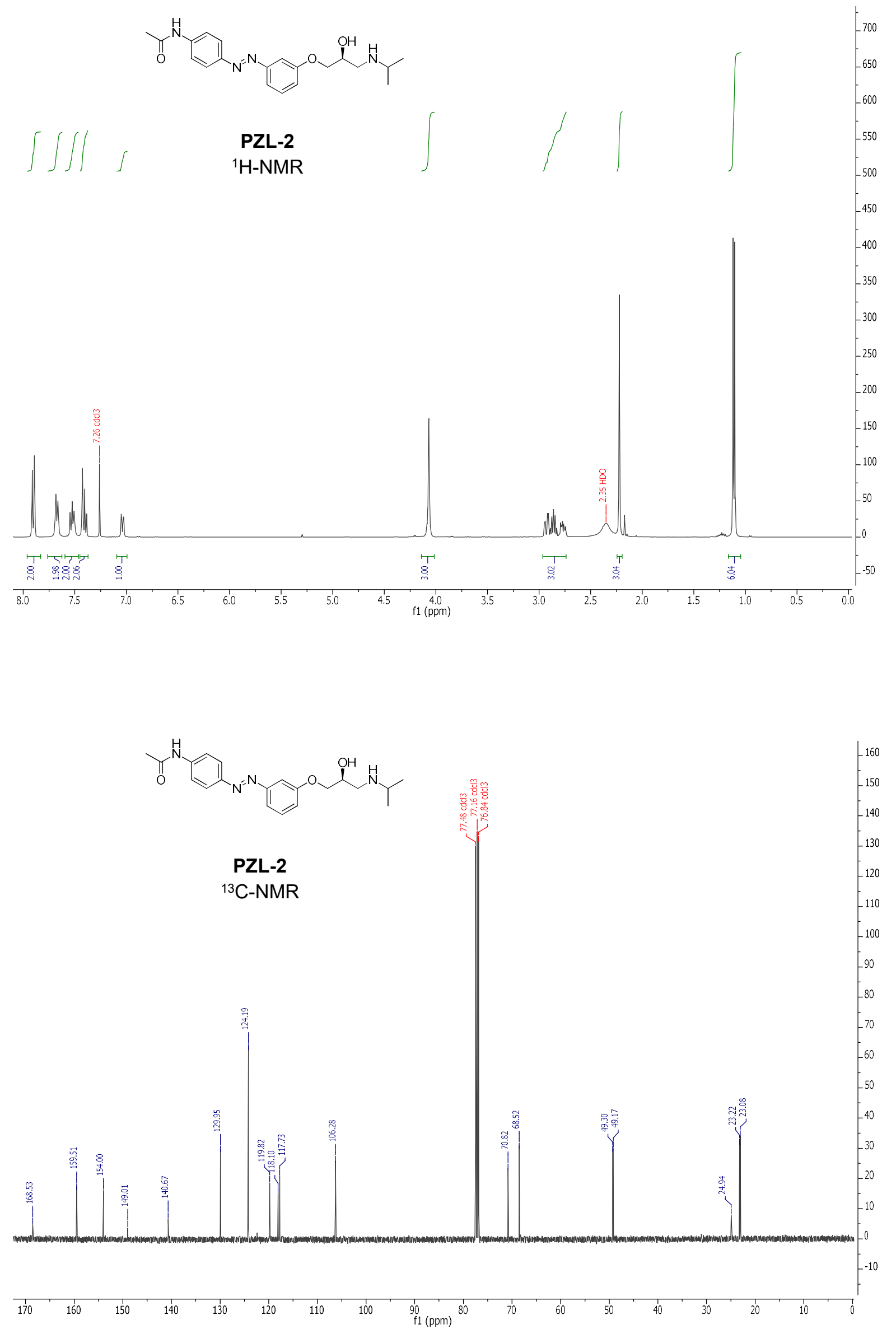

S23 

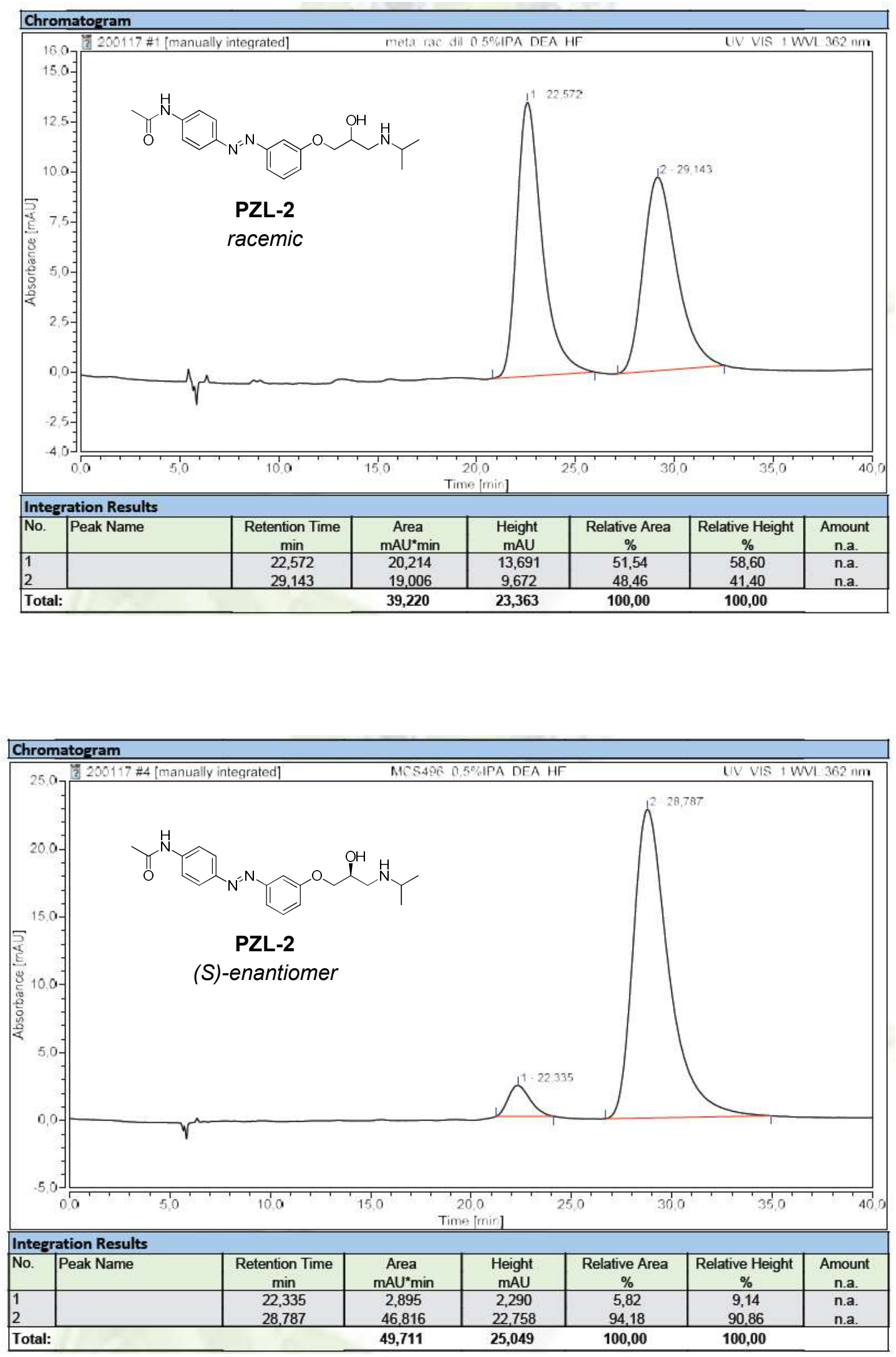

S24 

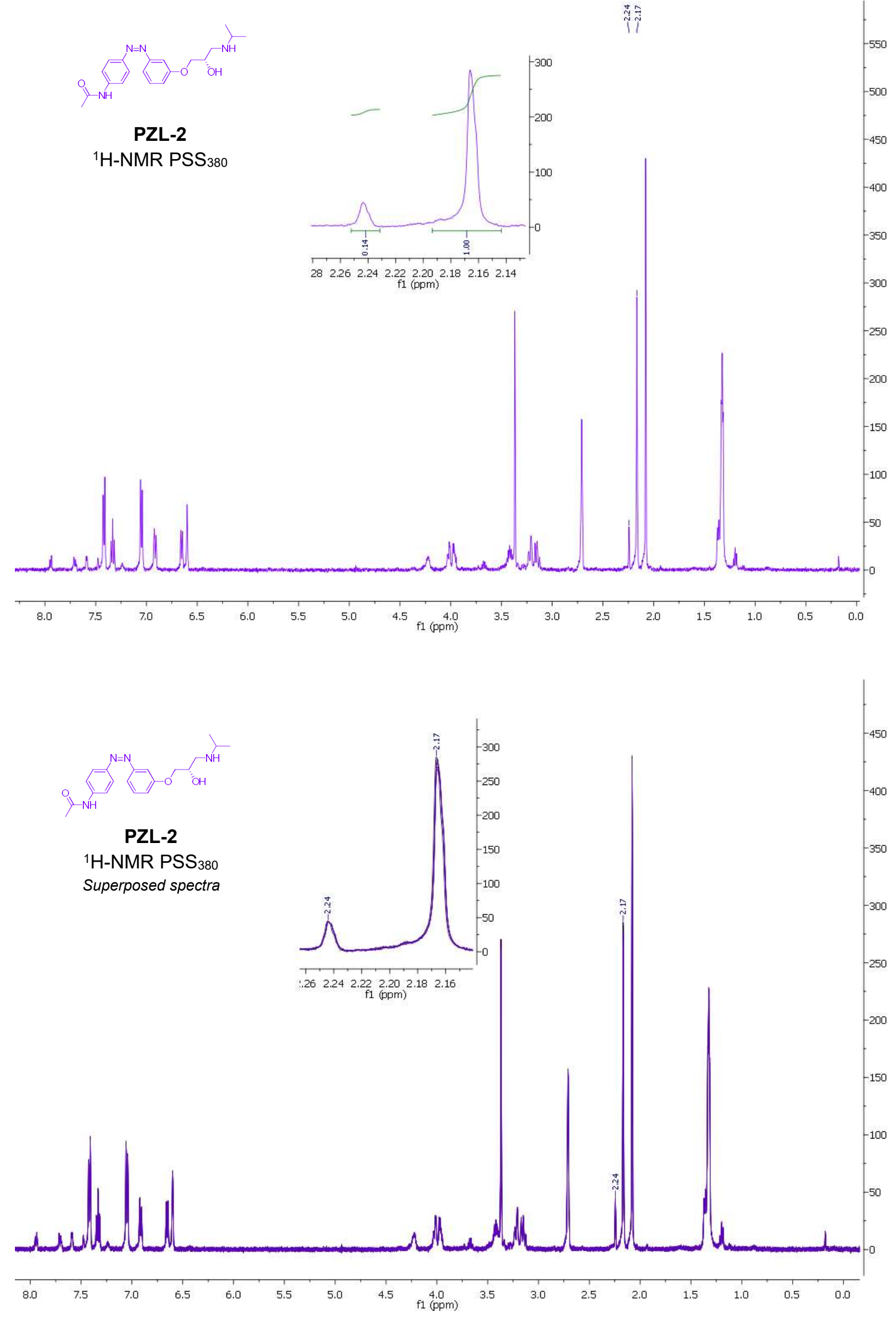

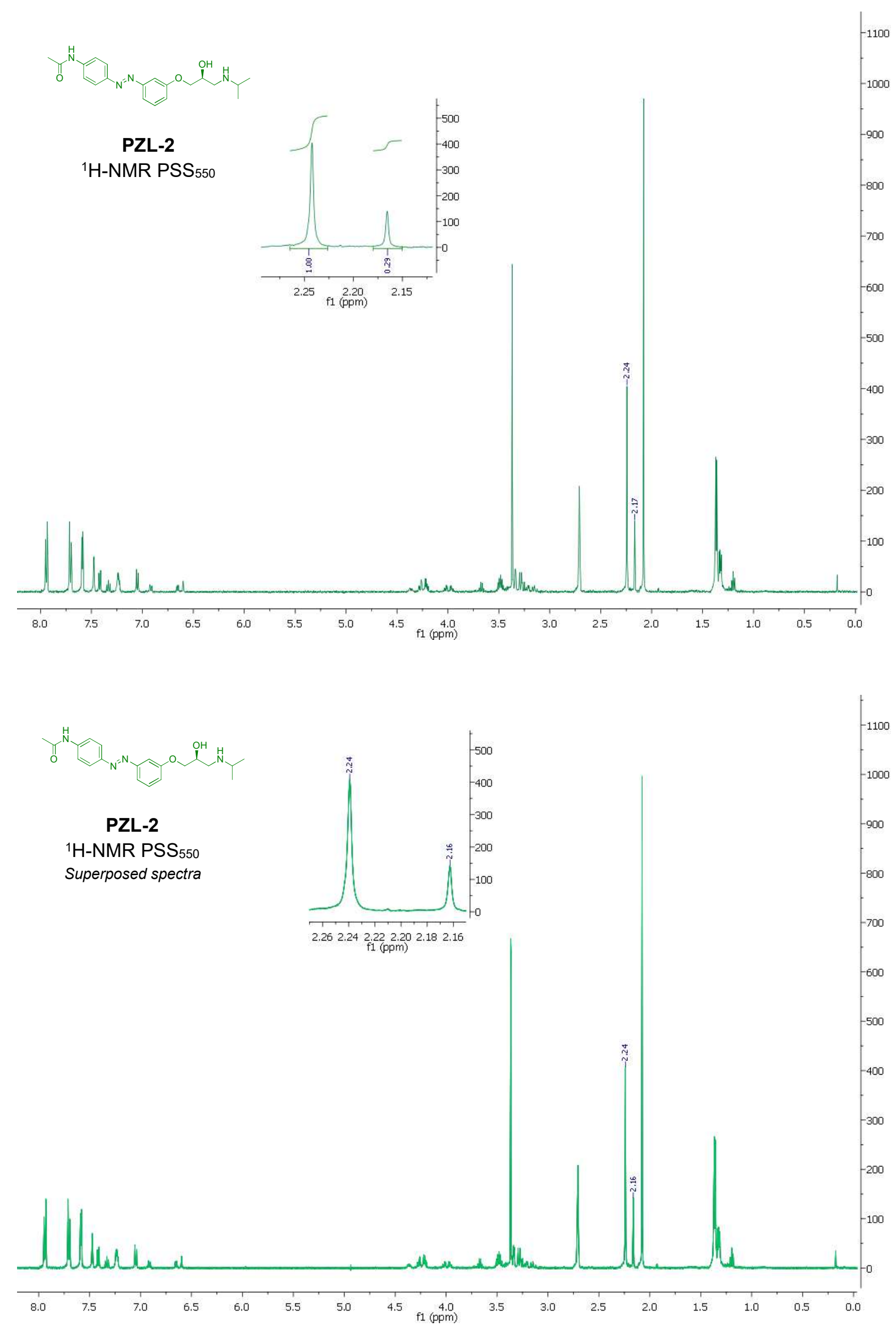

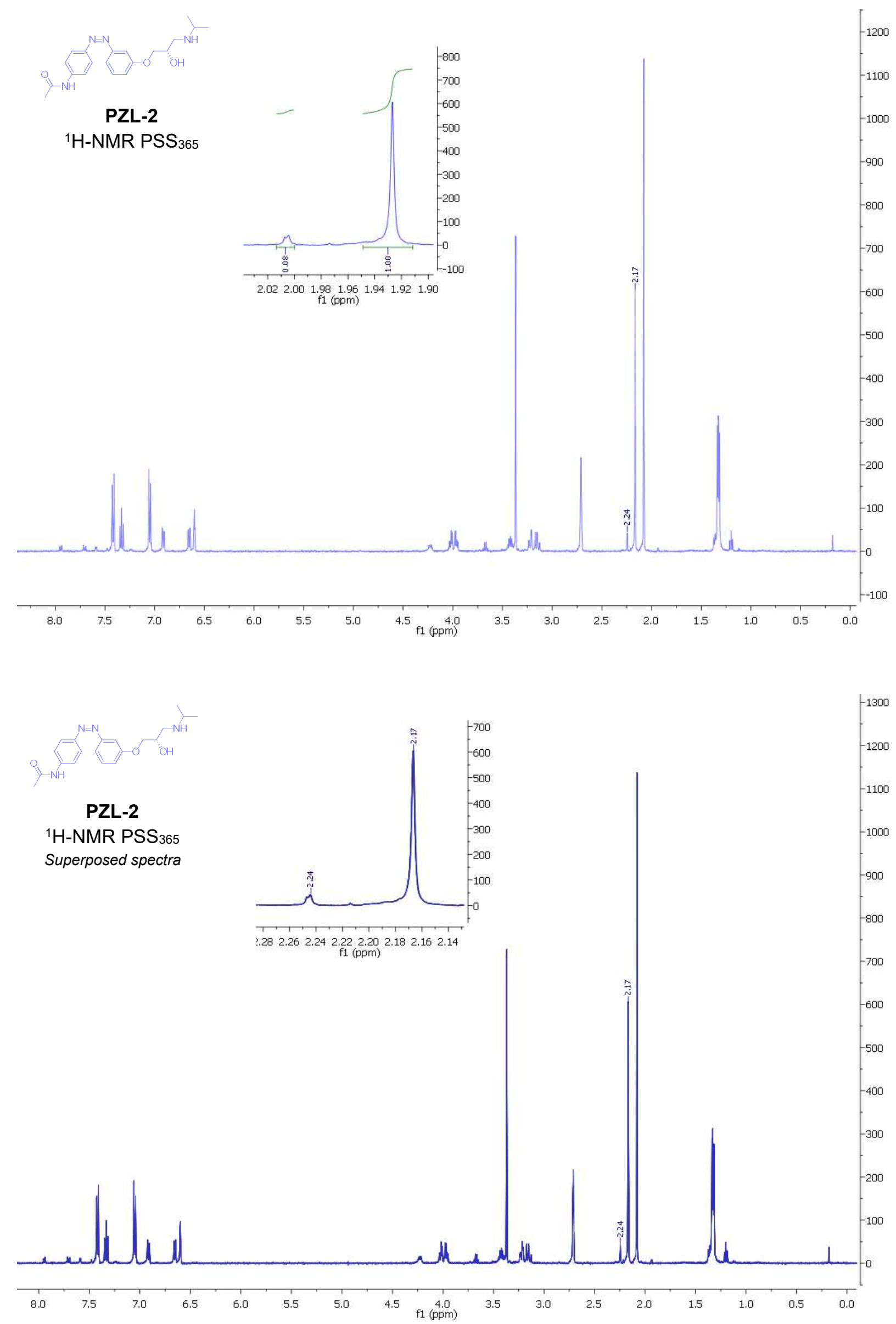

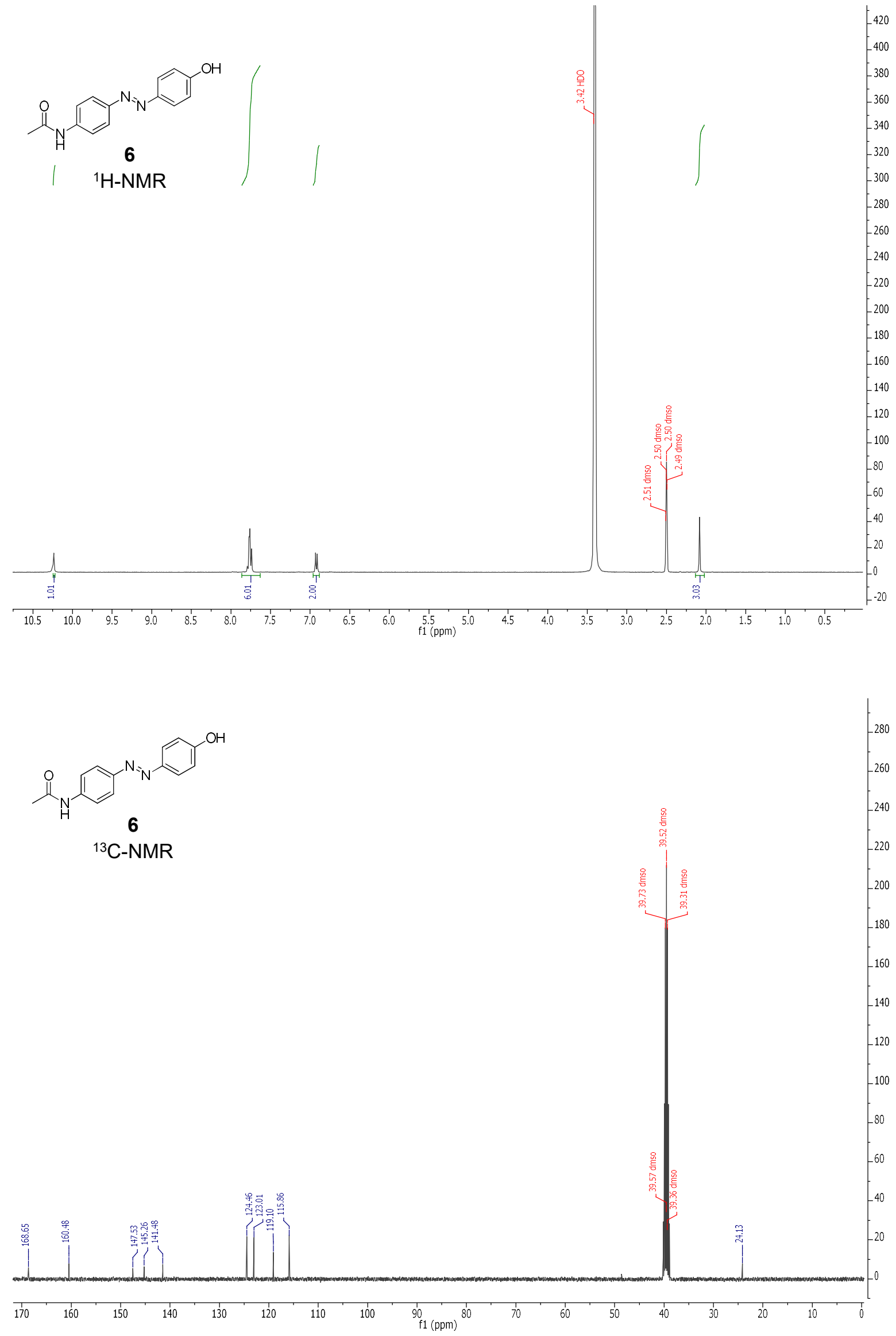

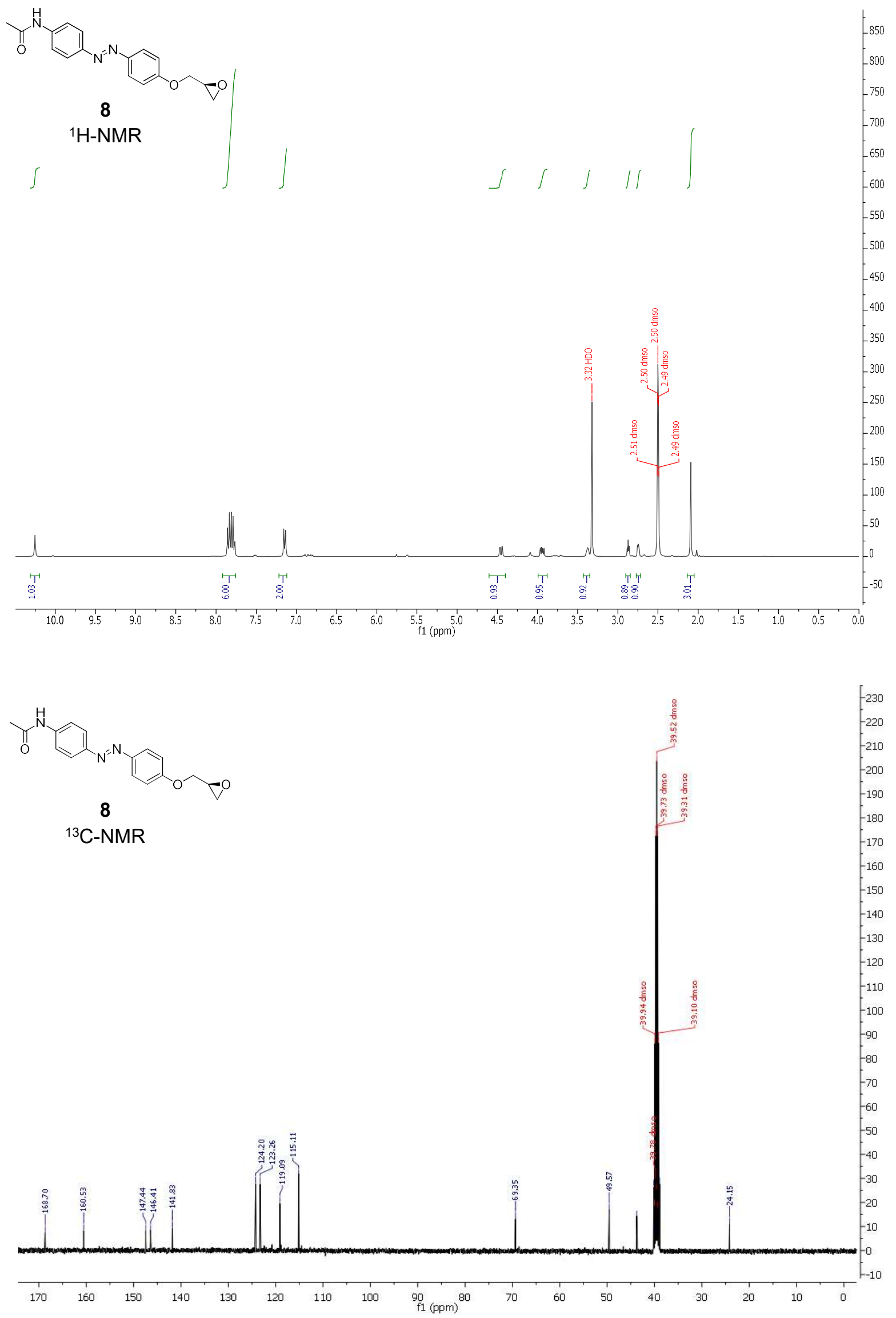

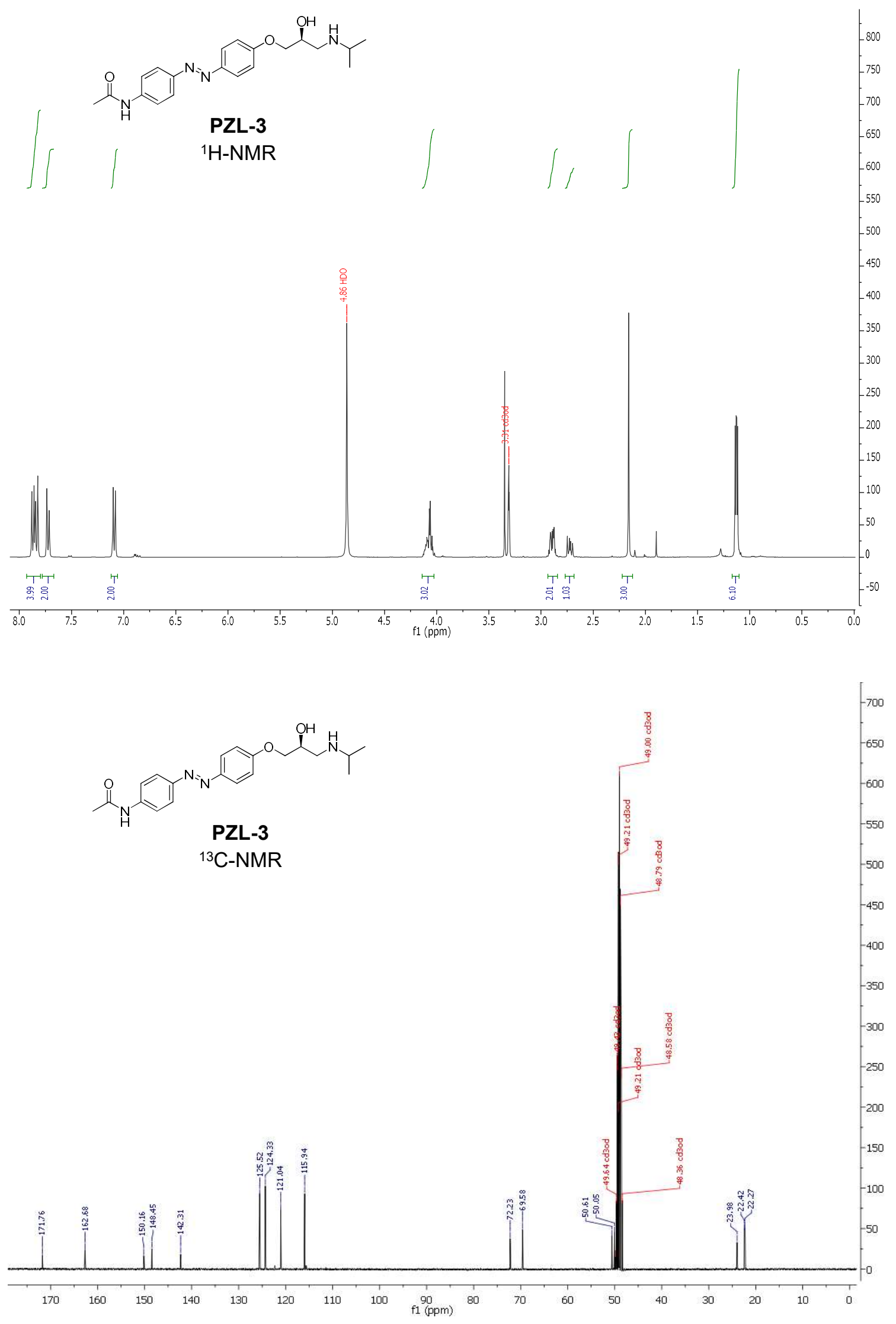

S30 

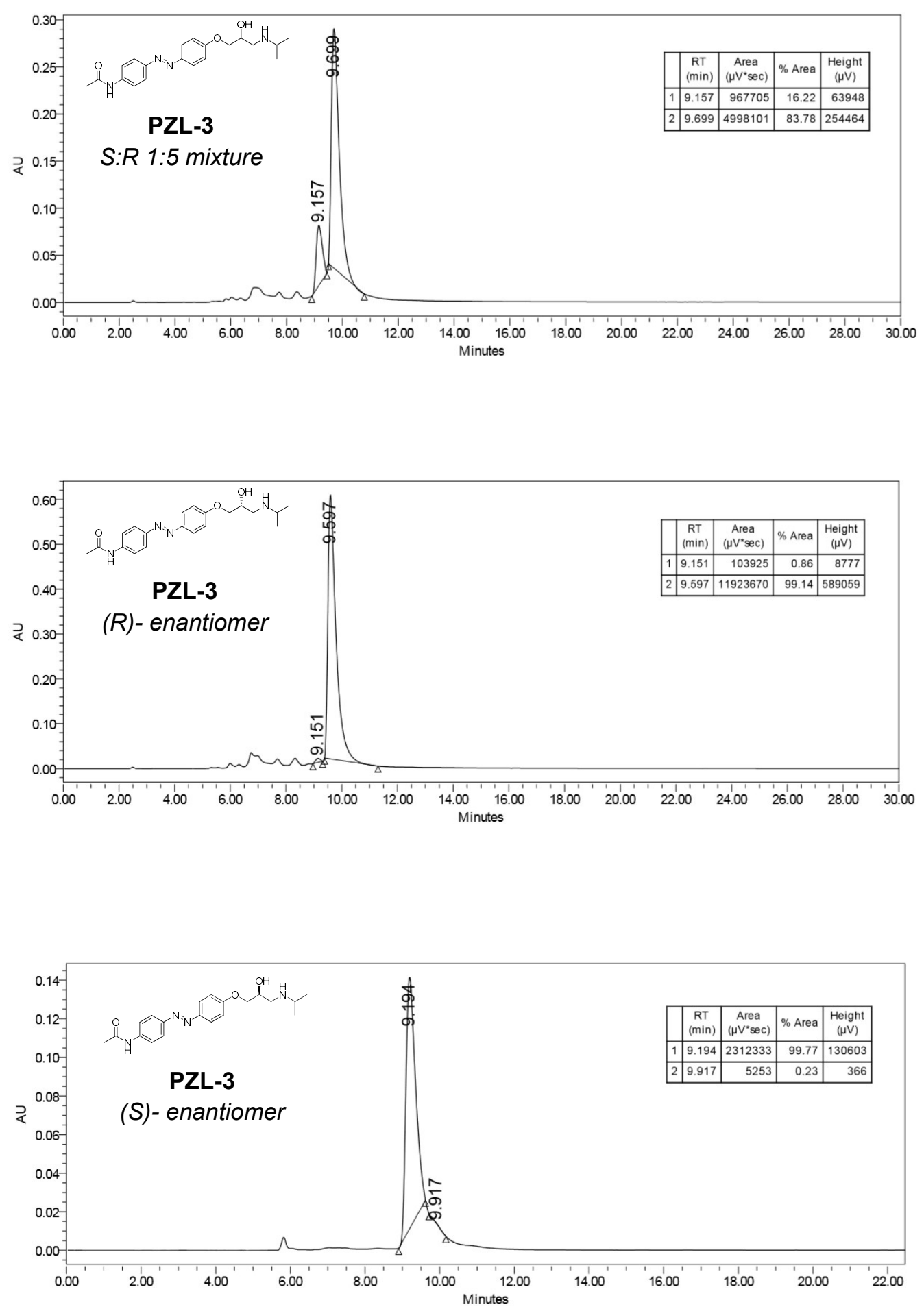


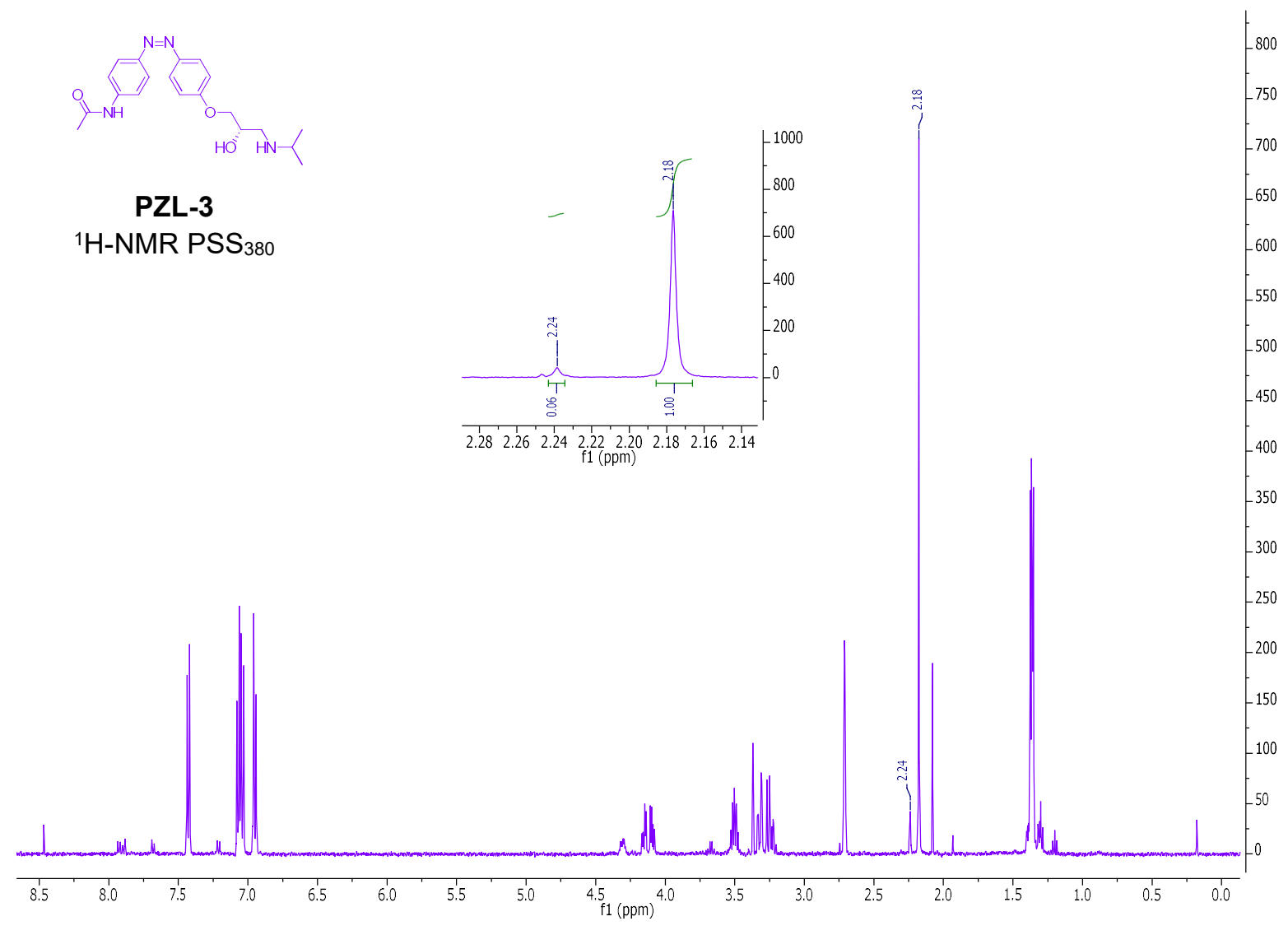

PZL-3

${ }^{1} \mathrm{H}-\mathrm{NMR} \mathrm{PSS}_{380}$

Superposed spectra

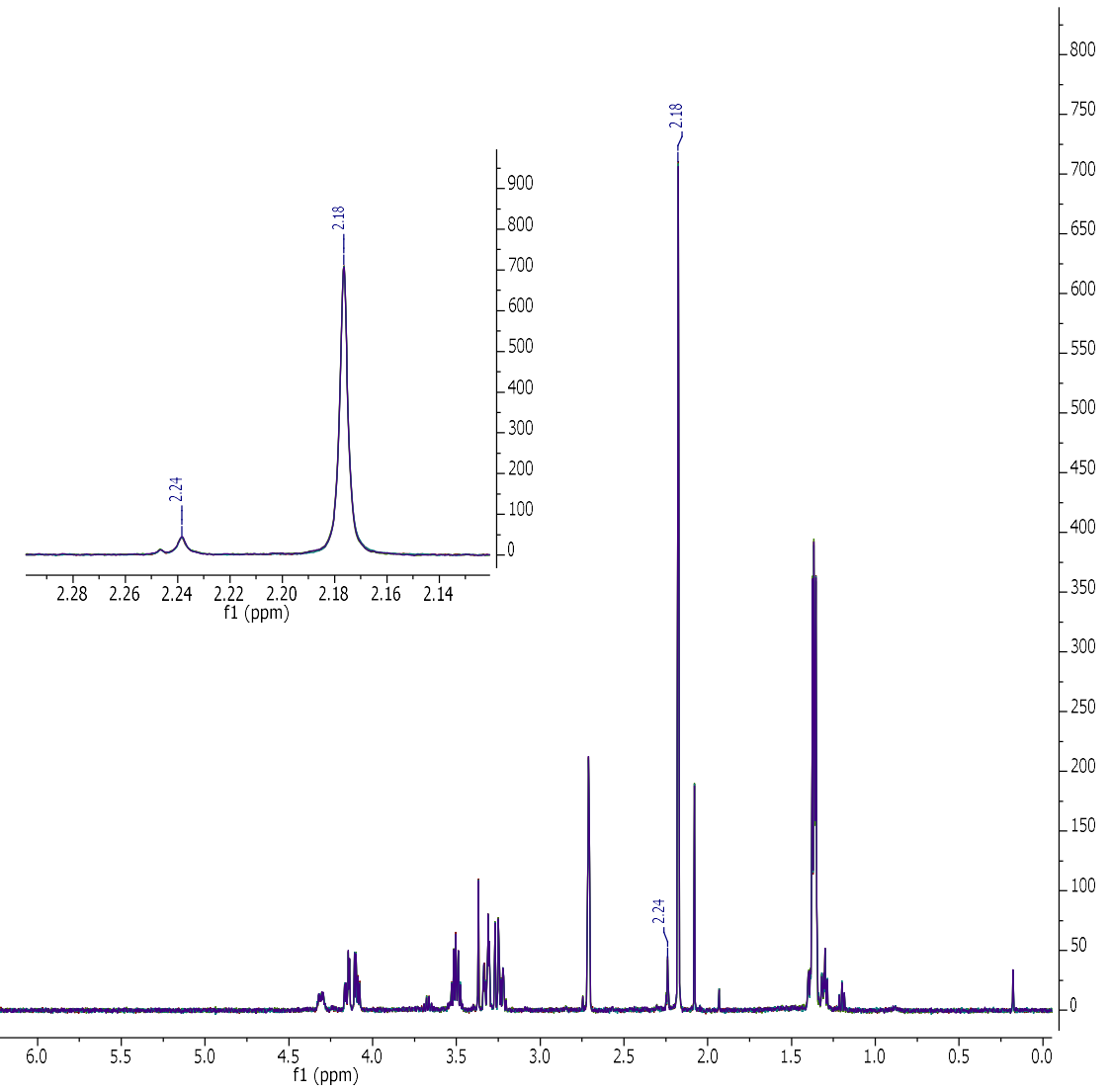



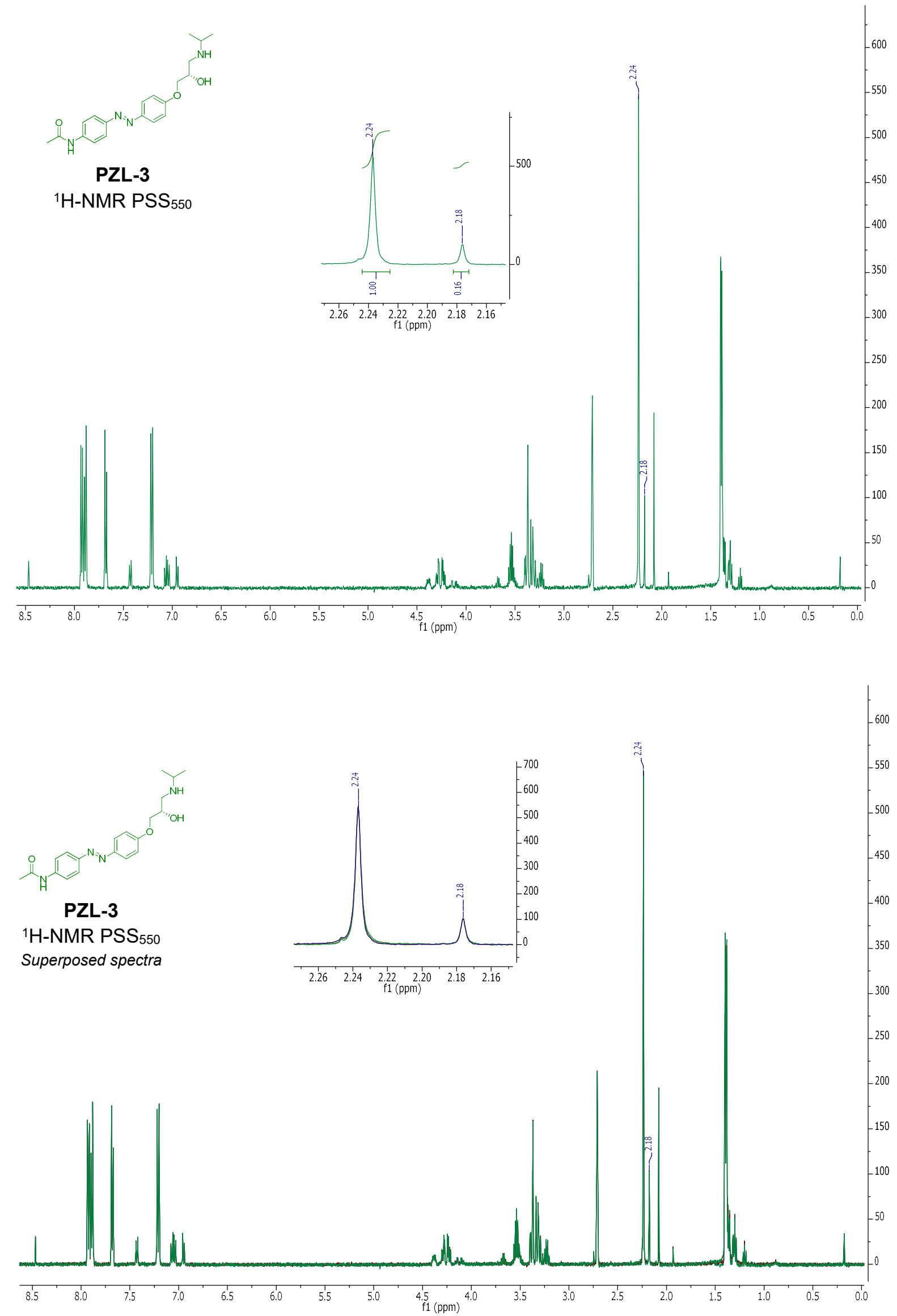